FERNANDA NERI DE SOUZA

EFEITO DO DIÂMETRO DO DUTO EM PARÂMETRO DE ESCOAMENTO DE POLPAS MINERAIS

São Paulo

2018 
FERNANDA NERI DE SOUZA

\section{EFEITO DO DIÂMETRO DO DUTO EM PARÂMETRO DE ESCOAMENTO DE POLPAS MINERAIS}

Dissertação apresentada à Escola Politécnica da Universidade de São Paulo como parte dos requisitos para a obtenção do título de Mestre em Ciências

\section{São Paulo}


FERNANDA NERI DE SOUZA

\section{EFEITO DO DIÂMETRO DO DUTO EM PARÂMETRO DE ESCOAMENTO DE POLPAS MINERAIS}

Dissertação apresentada à Escola Politécnica da Universidade de São Paulo como parte dos requisitos para a obtenção do título de Mestre em Ciências

Área de Concentração: Engenharia de Minas

Orientador: Prof. Dr. Arthur Pinto Chaves

São Paulo 


\section{Catalogação-na-publicação}

\section{Souza, Fernanda Neri de}

Efeito do diâmetro do duto em parâmetro de escoamento de polpas minerais. / F. N. Souza -- versão corr. -- São Paulo, 2018.

$69 \mathrm{p}$.

Dissertação (Mestrado) - Escola Politécnica da Universidade de São Paulo. Departamento de Engenharia de Minas e Petróleo.

1.Processamento mineral 2.Bombeamento 3.Carbonatito 4.Minério de ferro 5.Areia I.Universidade de São Paulo. Escola Politécnica. Departamento de Engenharia de Minas e Petróleo Il.t. 


\section{AGRADECIMENTOS}

Agradeço muito todo o apoio que recebi durante a execução deste trabalho.

Ao meu Professor Dr. Arthur Pinto Chaves, por me acolher desde o primeiro dia neste projeto.

À minha família, por ter me dado todas as oportunidades de ser quem eu sou hoje.

Ao Vinícius e ao Caetano, por estarem sempre do meu lado provendo todo o amor que é necessário para a vida.

À Eliana e Wilmar, por estarem sempre presentes e prontos para ajudar em qualquer situação.

Aos colegas Gabo, Lívia, Dimas, Juliana, Josy, Simone, Jatobá, Victor, Wellington pela companhia e pela troca de tantas ideias, almoços e cervejas.

À Valefertil, Vale e Porto de Areia Branca, por me conceder os materiais que foram objeto desse estudo.

Ao Instituto Tecnológico Vale e ao professor Laurindo de Salles Leal Filho, por todo o suporte.

Às equipes do Laboratório de Tratamento de Minérios e Resíduos Industriais, Laboratório de Caracterização Tecnológica e Laboratório de Fisico Química das Interfaces, por todo o convívio e apoio.

À CAPES, pelo suporte financeiro. 


\section{RESUMO}

O transporte de minério em tubos é feito em larga escala não somente em longas distâncias, (através de minerodutos); como também dentro da mina, seja no trajeto entre a mina e a usina, como no caso de minerais lavrados por desmonte hidráulico, ou entre as operações unitárias dentro da usina de beneficiamento. $O$ projeto dos sistemas de bombeamento de polpas requer 0 conhecimento das variáveis de escoamento, a perda de carga $(\Delta \mathrm{P})$ e a velocidade de deposição $(\mathrm{Vd})$. Discutem-se aqui alguns modelos de predição para tais variáveis. Apesar da irrefutável importância deste tipo de transporte, ainda não há consenso sobre a validade dos modelos existentes. Este trabalho teve como objetivo a análise comparativa dos modelos de velocidade de deposição propostos por Durand e Condolios (1952), Wasp et al. (1977) e Wilson et al. (2006), e os modelos de perda de carga propostos por Durand e Condolios (1952), Wasp et al. (1977) e Newitt et al. (1955) com os resultados de laboratório. A acurácia dos modelos, apesar das limitações de cada um, é crucial para que as variáveis de projeto do sistema de bombeamento sejam estabelecidas por meio do uso desses modelos. A comparação foi baseada em ensaios realizados em três test loops de diâmetros de 2", 3" e 4" com minério de ferro, carbonatito e areia, em concentrações de sólidos de 15\%, 30\% e 50\%. Trabalhando com minérios de diferentes granulometrias, densidades e polpas com concentrações diferentes pudemos analisar a interferência desses parâmetros no escoamento e no uso dos modelos propostos. Os modelos de $\mathrm{Vd}$ se mostraram bastante úteis, sendo que o modelo proposto por Durand e Condolios (1952) teve as melhores correlações para todos os materiais estudados. Já os modelos de perda de carga não mostraram correlações aceitáveis com os resultados de laboratório, endossando as indicações de alguns autores, como Chaves (2012) e Abulnaga (2002) que não recomendam o uso de modelos de predição de perda de carga nos cálculos de dimensionamento destes sistemas. Como alternativa, é possível utilizar plantas piloto e ensaios laboratoriais.

Palavras-chaves: Escoamento de polpas, bombas, velocidade de deposição, perda de carga. 


\begin{abstract}
Ore transportation in pipes is carried out on a large scale not only at long distances, such as ore pipelines, but also within the mine, or in the path between the mine and the plant, as the case of minerals drawn by hydraulic dismantling, or between operations within the beneficiation plant. The design of the slurry pumping systems requires the knowledge of the flow variables, as the head loss $(\Delta \mathrm{P})$ and the deposition velocity $(\mathrm{Vd})$. Some prediction models for such variables are discussed in this dissertation. Despite the irrefutable importance of this type of transportation, there is still no agreement on the validity of the existing models. Their limitations make unfeasible to use them, and much more is necessary to improve in this field. This work aimed to make a comparative analysis of the deposition velocity models proposed by Durand and Condolios (1952), Wasp et al. (1977) and Wilson et al. (2006), and the head loss models proposed by Durand and Condolios (1952), Wasp et al. (1977) and Newitt et al. (1955) with laboratory results. The accuracy of the models, despite the limitations of each one, is crucial if pumping system design variables are established using these models. The comparison was based on laboratory tests performed on three diameter test loops, 2 ", 3" and 4 " with iron ore, carbonatite and sand a concentrations of $15 \%, 30 \%$ and $50 \%$ in weight solids concentrations. Working with different ore grain sizes and densities ores and pulps with different concentrations we can analyze the interference of these parameters in the flow and in the models use. The Vd models were very useful, and the Durand and Condolios (1952) model showed the best correlations for all ores studied. However, the head loss models did not show acceptable correlations with the laboratory results, endorsing the indications of some authors, such as Chaves (2012) and Abulnaga (2002), who do not recommend the use of prediction models for head loss in these systems sizing. Alternatively, it is possible to use pilot plants and laboratory tests.
\end{abstract}

Keywords: Slurry flow, pumps, deposition velocity, head loss. 


\section{ÍNDICE DE ILUSTRAÇÕES}

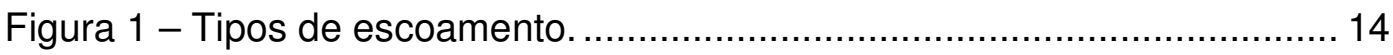

Figura 2 - Tipos de fluxo de polpas minerais............................................. 15

Figura 3 - Viscosidade aparente para fluidos dependente do tempo............... 20

Figura 4 - Exemplo de reograma de polpa mineral....................................... 22

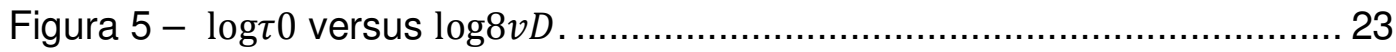

Figura 6 - Perdas de Carga vs Velocidade de escoamento. .......................... 27

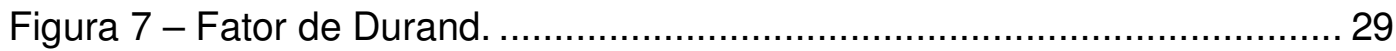

Figura 8 - Ábaco de Wilson para velocidade de deposição de partículas ....... 30

Figura 9 - Test loop de bombeamento de 2".............................................. 36

Figura 10 - Test loop de bombeamento de 3" e 4" ........................................ 36

Figura 11 - Misturador do sistema de 3" e 4" ................................................. 37

Figura 12 - Trecho de tubulação transparente na unidade de 3" e 4".............. 37

Figura 13 - Medidores de pressão dos loops.............................................. 38

Figura 14 - Medidor de vazão e velocidade de escoamento ............................ 38

Figura 15 - Exemplo de escoamento com leito fixo ........................................ 41

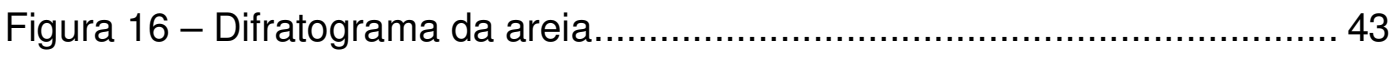

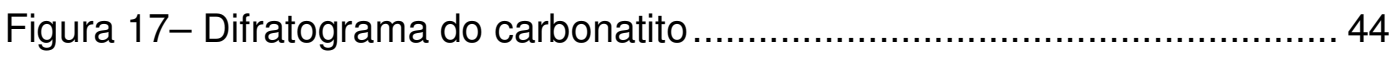

Figura 18- Difratograma do minério de ferro.................................................. 44

Figura 19 - Curvas granulométricas dos materiais testados ............................ 45

Figura 20 - Desmontagem do duto entupido com polpa de areia .................... 47

Figura 21 - Curvas $V X \Delta P$ para areia a $15 \%$ (continua) ................................. 47

Figura 22- Curvas V X $\Delta \mathrm{P}$ para ferro a 15\% (continua) ................................... 49

Figura 23- Curvas $\mathrm{V} X \Delta \mathrm{P}$ para ferro a $30 \%$ (continua) …............................. 50

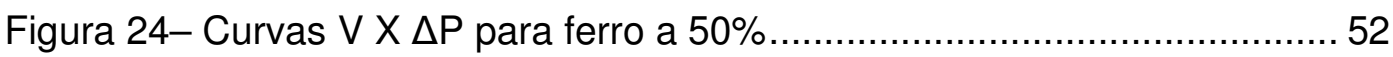

Figura 25- Curvas $\mathrm{V} X \Delta \mathrm{P}$ para carbonatito a $15 \%$ (continua) .........................53 
Figura 26- Curvas $\mathrm{V} X \Delta \mathrm{P}$ para carbonatito a $30 \%$ (continua) ..........................54

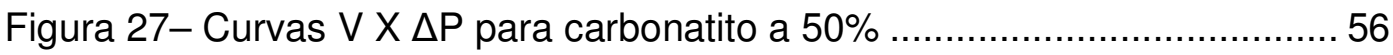

Figura 28 - Comparação de Vd real com os modelos para areia ..................... 59

Figura 29 - Comparação de Vd real com os modelos para ferro ........................60

Figura 30 - Comparação de Vd real com os modelos para carbonatito

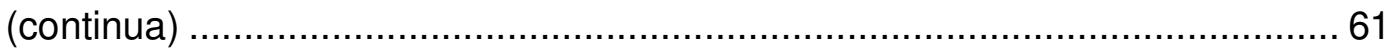

Figura 31 - Comparação de $\Delta \mathrm{P}$ real com os modelos para areia..................... 64

Figura 32 - Comparação de $\Delta \mathrm{P}$ real com os modelos para ferro ..................... 64

Figura 33 - Comparação de $\Delta \mathrm{P}$ real com os modelos para carbonatito ............65 


\section{ÍNDICE DE TABELAS}

Tabela 1 - Modelos matemáticos de comportamento de fluidos...................... 18

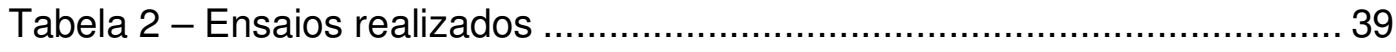

Tabela 3 - Parâmetros de granulometria ……............................................... 46

Tabela 4 - Densidades dos materiais e das polpas minerais .......................... 46

Tabela 5 - Compilação de velocidades de deposição e perdas de carga mínimas de escoamento ........................................................................ 57 


\section{LISTA DE ABREVIATURAS E SIGLAS}

Adimensional de homogeneidade da polpa

$(-)$

$\mathrm{c} / \mathrm{c}_{\mathrm{a}}$

$\Delta \mathrm{P} \quad$ Gradiente de pressão ou perda de carga

(Kpa ou mbar)

Cd Coeficiente de arraste

$(-)$

Cv Concentração volumétrica de sólidos

Cw Concentração mássica de sólidos

D Diâmetro interno do tubo

$\mathrm{d}_{50} \quad$ Tamanho médio da partícula

$\mathrm{d}_{\mathrm{s}} \quad$ Diâmetro de Sauter da partícula

dV/dy Taxa de deformação

F $\quad$ Fator de fricção de Fanning

$(-)$

$f_{D} \quad$ Fator de fricção de Darcy

$\mathrm{f}_{\mathrm{f}} \quad$ Fator de fricção do fluido

$\mathrm{F}_{\mathrm{I}} \quad$ Fator de fricção de Durand e Condolios

Fr Número de Froude

G Aceleração da Gravidade

H Altura manométrica

I Coeficiente de fricção hidráulico da polpa

Iw Coeficiente de fricção hidráulico da água

K Coeficiente da lei de potência

K Constante de Durand para perda de carga

$(-)$

$\mathrm{k}_{2} \quad$ Constante de Newitt para perda de carga

k Constante de distribuição da concentração

L Comprimento do tubo

$\mathrm{m}_{\mathrm{l}} \quad$ massa de líquido 


\begin{tabular}{|c|c|c|}
\hline$m_{p}$ & massa de polpa & $(\mathrm{Kg})$ \\
\hline $\mathrm{m}_{\mathrm{s}}$ & massa de sólidos & $(\mathrm{Kg})$ \\
\hline $\mathrm{N}$ & Índice da lei de potência & $(-)$ \\
\hline$\eta$ & Coeficiente de rigidez & $(-)$ \\
\hline $\mathrm{Re}$ & Número de Reynolds & $(-)$ \\
\hline$S_{p}$ & Área superficial da partícula & $\left(m^{2}\right)$ \\
\hline $\mathrm{V}$ & Velocidade de escoamento & $(\mathrm{m} / \mathrm{s})$ \\
\hline $\mathrm{V}_{\infty}$ & Velocidade terminal da partícula & $(\mathrm{mm} / \mathrm{s})$ \\
\hline $\mathrm{V}_{\mathrm{d}}$ & Velocidade de deposição & $(\mathrm{m} / \mathrm{s})$ \\
\hline$V_{t}$ & Velocidade de transição & $(\mathrm{m} / \mathrm{s})$ \\
\hline$E$ & Coeficiente de rugosidade do tubo & $(\mathrm{m})$ \\
\hline Z & Tensão de cisalhamento & $(\mathrm{Pa})$ \\
\hline$\zeta_{w}$ & Tensão de cisalhamento na parede do tubo & $(\mathrm{Pa})$ \\
\hline$\mu_{\mathrm{a}}$ & Viscosidade aparente & (Pa.s) \\
\hline$\mu_{\mathrm{b}}$ & Viscosidade plástica & (Pa.s) \\
\hline$\mu_{\mathrm{e}}$ & Viscosidade efetiva & (Pa.s) \\
\hline$\mu_{f}$ & Viscosidade do fluido (água) & (Pa.s) \\
\hline $\mathrm{N}$ & Viscosidade cinemática & $\left(\mathrm{m}^{2} / \mathrm{s}\right)$ \\
\hline$\rho_{\mathrm{l}}$ & Densidade do líquido & $\left(\mathrm{Kg} / \mathrm{m}^{3}\right)$ \\
\hline$\rho_{p}$ & Densidade da polpa & $\left(\mathrm{Kg} / \mathrm{m}^{3}\right)$ \\
\hline$\rho_{\mathrm{s}}$ & Densidade do sólido & $\left(\mathrm{Kg} / \mathrm{m}^{3}\right)$ \\
\hline $\mathrm{T}$ & Tensão de escoamento & $(\mathrm{Pa})$ \\
\hline$\Psi$ & Esfericidade da partícula & $(-)$ \\
\hline
\end{tabular}




\section{SUMÁRIO}

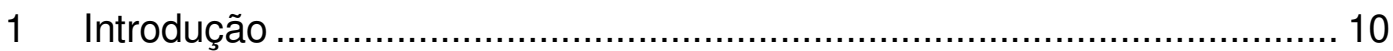

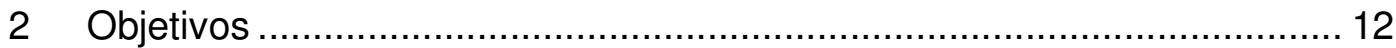

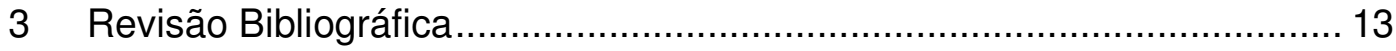

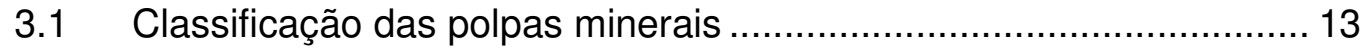

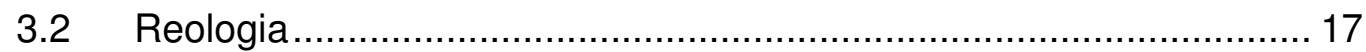

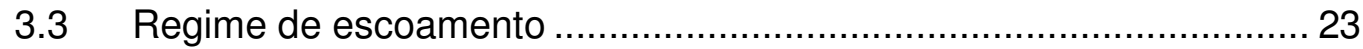

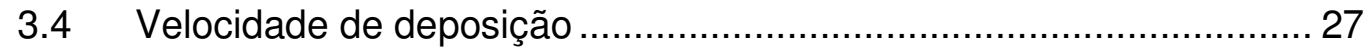

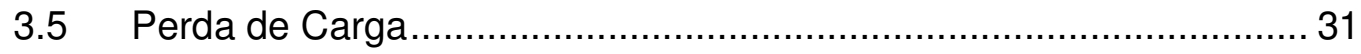

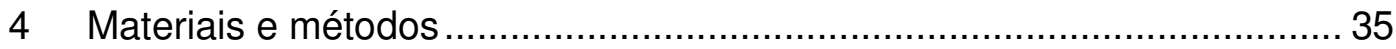

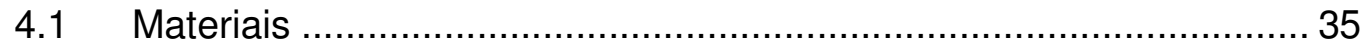

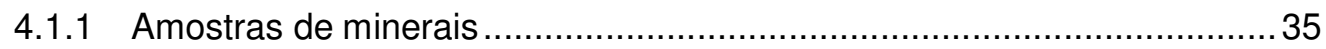

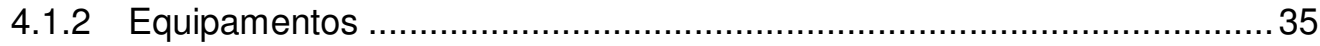

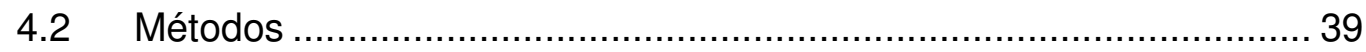

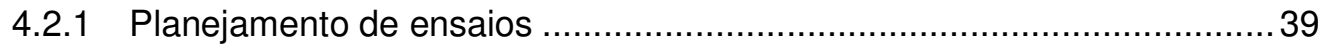

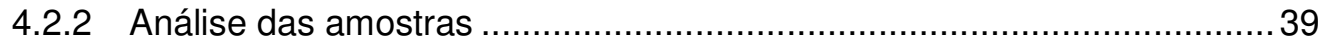

4.2.3 Preparação das polpas minerais ......................................................... 40

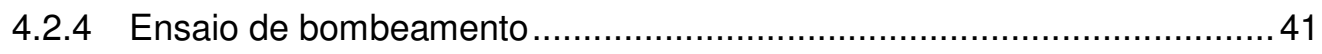

5 Análise e discussão dos resultados ...................................................... 43

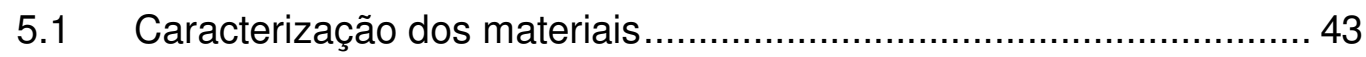

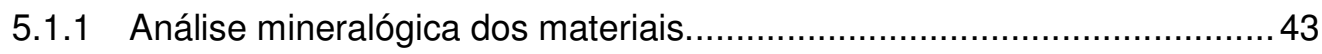

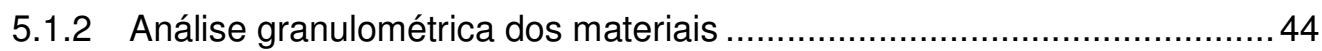

5.1.3 Ensaios de densidade ...................................................................... 46

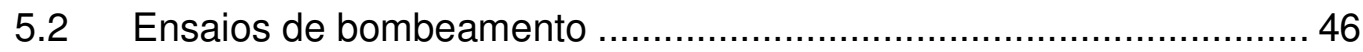

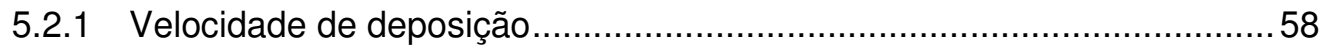

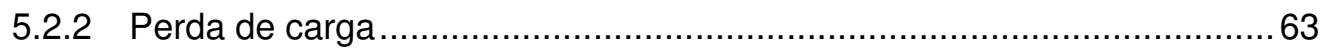

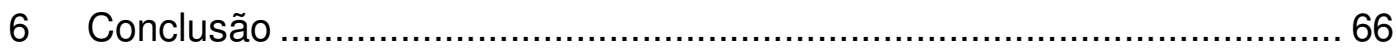

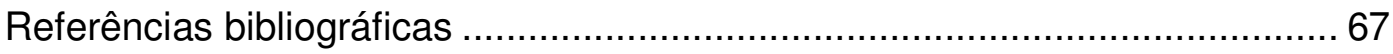
I 


\section{INTRODUÇÃO}

A maior parte dos minérios é beneficiada a úmido, salvo aqueles que têm alguma restrição ao contato com a umidade, como é o caso dos calcários para a produção de cimento ou sais solúveis. O bombeamento de polpas é a base para o transporte entre as operações unitárias de beneficiamento mineral a úmido.

O uso do bombeamento para o transporte de polpas minerais se estende desde a lavra, no caso dos desmontes hidráulicos e das dragagens, até o escoamento da produção da mina, como nos minerodutos, passando por uma infinidade de usos entre estes dois fins, como o transporte da mina à usina, o transporte entre as operações unitárias na usina de beneficiamento e o transporte de rejeitos do processo.

Para o entendimento completo do funcionamento de sistemas de bombeamento de polpas minerais, é essencial conhecer os parâmetros que interferem diretamente nesta atividade, como as condições de escoamento, velocidades de transição, comportamentos do escoamento em tubos de diferentes diâmetros e também concentração de sólidos, tamanho e forma da partícula e mineralogia da polpa processada (SILVA, GARCIA, et al., 2015).

O dimensionamento de um sistema seguro de transporte por bombeamento está ligado ao conhecimento das características reológicas da polpa de modo a garantir que o dimensionamento não seja superestimado, evitando altas pressões, desgaste excessivo das tubulações e alto consumo de energia (CHAVES, 2012).

No projeto de um sistema de bombeamento, os engenheiros precisam garantir uma velocidade tal que não haja deposição de partículas no duto, no entanto, esta velocidade precisa ser ajustada para que a perda de carga e os desgastes por abrasão (sólidos contra as paredes do tubo) sejam minimizados, assim como o custo operacional. Assim sendo, logo no início do projeto são necessárias informações como regime de escoamento, velocidade de deposição das partículas e perda de carga, além das características físicas do sistema e da polpa, como o diâmetro e comprimento do duto, singularidades da 
tubulação, densidade da polpa, do fluido e do minério e o tamanho das partículas que serão transportadas.

Em projetos de bombeamento de polpa, a formação de leito não é admissível. A área ocupada pelo leito dentro do tubo diminui a área de escoamento, causando aumento de perda de carga significativo. Além disso, a formação de um leito fixo pode evoluir rapidamente para a obstrução total do tubo, causando perdas materiais e operacionais ao processo. Brum (2017) pontua que nos casos de transporte em longas distâncias, um dos problemas mais sérios a ser evitado é a obstrução da linha pelo próprio material e a compactação do material sedimentado que impeça a repolpagem. A retomada da operação nestes casos pode ser muito trabalhosa e custosa.

As características dos sistemas são dadas, mas são necessários modelos para predizer a velocidade de deposição e a perda de carga. Desde os anos 50, diversos pesquisadores têm trabalhado em modelos matemáticos que fossem capazes de predizer as velocidades de deposição e as perdas de carga de um sistema de escoamento de polpas. Os modelos de Durand e Condolios (1952), Wasp et al. (1977), Wilson et al. (2006), Jacobs (2005) e Pinto (2012) são exemplos deste esforço.

Todos os modelos de predição consideram, em primeiro lugar, que as partículas contidas nas polpas minerais estejam em movimento, o que nos leva à primeira variável de interesse, a velocidade de deposição $\left(V_{d}\right)$, que é a velocidade exigida para que o escoamento ocorra sem deposição de partículas no tubo. A velocidade de deposição, por sua vez, depende do tamanho das partículas $\left(d_{50}\right)$ e da densidade do sólido $\left(\rho_{\mathrm{s}}\right)$, da concentração mássica de sólidos na polpa $\left(C_{w}\right)$, densidade da polpa $\left(\rho_{p}\right)$ e da viscosidade do fluido carreador $\left(\mu_{\mathrm{f}}\right)$.

Uma vez definida a velocidade do escoamento, a perda de carga é a variável mais importante para o dimensionamento do sistema e escolha dos equipamentos. Jacobs (2005) pontua que a predição da perda de carga como uma função de variáveis independentes como velocidade de escoamento, diâmetro do tubo, tamanho médio da partícula e distribuição granulométrica é primordial para o desenvolvimento do projeto. 


\section{OBJETIVOS}

Este trabalho tem como objetivo principal a análise comparativa entre os modelos de velocidade de deposição propostos por Durand (1952), Wasp et al. (1977) e Wilson et al. (2006), e os modelos de perda de carga propostos por Durand e Condolios (1952), Wasp et al. (1977) e Newitt et al. (1955) com os resultados obtidos em laboratório. A validade dos modelos, apesar das limitações de cada um, é crucial para que as variáveis de projeto de um sistema de bombeamento de polpas minerais sejam estabelecidas. 


\section{REVISÃo BIBLIOGRÁFICA}

Segundo Brum (2017), algumas condições devem ser cumpridas para que seja possível realizar o transporte de uma polpa mineral através de uma tubulação. São elas:

- o sólido deve facilmente misturar-se e separar-se do fluido;

- o sólido não pode reagir quimicamente nem com o fluido nem com o material da tubulação;

- as partículas não podem ser aglomeráveis, o que pode causar a obstrução do tubo;

- o desgaste e a ruptura das partículas durante o escoamento não podem ser prejudiciais ao processo;

- a concentração de sólidos deve ser adequada.

\subsection{CLASSIFICAÇÃO DAS POLPAS MINERAIS}

O entendimento do comportamento reológico da polpa de minério é indispensável para que possamos aplicar ao modelo de escoamento as adequações necessárias a cada tipo de fluido.

Os fluidos podem ser classificados de acordo com o seu comportamento reológico como newtonianos e não newtonianos.

Fluidos newtonianos tem como característica a viscosidade de cisalhamento constante, ou seja, no diagrama reológico (taxa de cisalhamento vs tensão de cisalhamento), além disso, quando não é aplicada nenhuma tensão de cisalhamento, a taxa de cisalhamento é zero, ou seja, o diagrama reológico do fluido newtoniano passa pela origem (BARNES, HUTTON e WATERS, 1993).

Os fluidos não newtonianos são aqueles cujos diagramas reológicos são não lineares ou não passam pela origem, ou seja, quando a viscosidade aparente $\left(\mu_{\mathrm{a}}\right)$ não é constante em uma certa condição de pressão e temperatura e depende das condições de escoamento, como geometria do escoamento, taxa de cisalhamento (CHHABRA e RICHARDSON, 1999).

A maior parte das polpas minerais, como lamas e suspensões de rochas, se comporta como fluidos de Bingham (CHAVES, 2012) (JACOBS, 2005). Fluidos de Bingham são caracterizados pela existência de uma tensão de escoamento 
que precisa ser superada para que o fluido se deforme ou comece a escoar e pela viscosidade $(\mu)$ constante (CHHABRA e RICHARDSON, 1999).

A Figura 1 mostra o comportamento de diferentes tipos de fluidos:

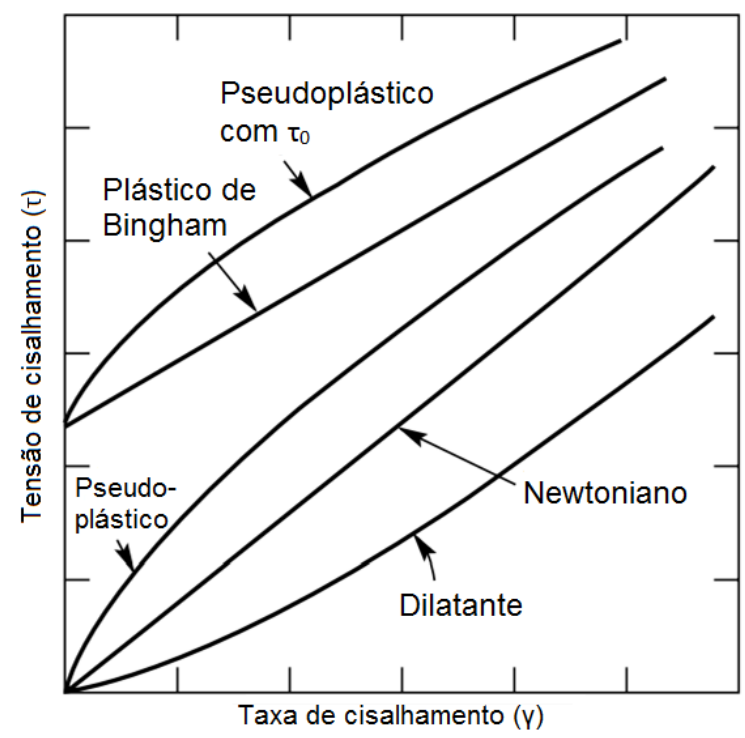

Figura 1 - Tipos de escoamento.

Fonte: Adaptado de Chhabra e Richardson (1999).

Chaves (2012) aponta que o comportamento de polpas minerais, quando submetidas a bombeamento, difere muito dos líquidos homogêneos, pois há de se considerar, além das propriedades do fluido, as propriedades do sólido e as interações entre as partículas. De fato, quando se trata de escoamento de polpas minerais, é possível observar o comportamento apresentado na Figura 2. 


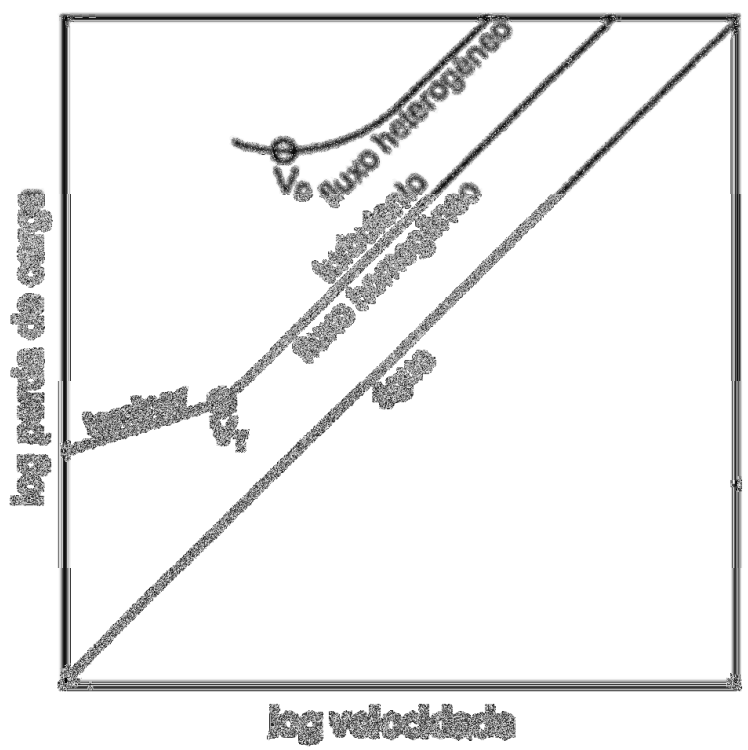

Figura 2 - Tipos de fluxo de polpas minerais.

Fonte: (CHAVES, 2012).

A Figura 2 trata de dois tipos de polpas diferentes: polpas homogêneas e polpas heterogêneas. A primeira tem $V_{t}$ (velocidade de transição) como ponto de transição entre o regime laminar e o turbulento. Já a segunda é caracterizada pelo ponto de mínima perda de carga $V_{d}$ (velocidade de deposição).

Wasp et al. (1977) definiram os conceitos de homogeneidade e heterogeneidade do escoamento de polpas minerais da seguinte maneira:

- polpas homogêneas: os sólidos são distribuídos de maneira uniforme por todo o volume do fluido. Normalmente são polpas de alta concentração de sólidos e partículas de tamanho pequeno. Esta configuração em geral causa alguns efeitos no sistema, como o aumento da viscosidade comparado com a viscosidade do fluido. Em geral apresentam comportamento não newtoniano, e as forças inerciais que agem sobre as partículas não são significativas.

- polpas heterogêneas: nestes sistemas a distribuição dos sólidos no fluido não é uniforme. Em dutos horizontais, há um gradiente de concentração no eixo axial, mesmo em altas velocidades. As forças inerciais são de extrema importância para o comportamento do escoamento, no entanto a viscosidade não é alterada de maneira 
significativa. Estes sistemas tendem a ter baixa concentração de sólidos e maiores tamanhos de partículas.

No entanto, a classificação das polpas em homogêneas e heterogêneas transcende a definição dada por Wasp et al. (1977). Diversos autores propuseram maneiras de classificar as polpas segundo a homogeneidade, como por exemplo Durand (1952), que estabeleceu como parâmetro para um escoamento heterogêneo um critério baseado somente na distribuição granulométrica. Desta maneira, as polpas que contivessem partículas maiores que $200 \mu \mathrm{m}$ seriam consideradas heterogêneas. A limitação deste modelo está em sua aplicabilidade somente em sistemas de água e areia. Outros sistemas não podem ser classificados dessa maneira.

Wasp et al. (1977) assinalam que, apesar de não existir de fato uma polpa mineral homogênea, esta classificação é necessária. Para isto, ele criou um adimensional $\left(C / C_{a}\right)$, definido pela razão da concentração volumétrica de sólidos a uma distância de 0,08D do topo para o centro do duto (sendo D o diâmetro do tubo). Para uma razão $C / C_{a}$ próxima de 1 , a polpa é definida como homogênea. A polpa passa a ser heterogênea quando este valor chega a 0,8. Esta classificação depende do regime de escoamento da polpa, já que a homogeneidade do escoamento aumenta com a velocidade e turbulência.

Em escoamento de fluidos multifásicos em dutos horizontais, o movimento dos sólidos pode acontecer de diferentes maneiras. Lahiri (2010) classificou estes fluxos da seguinte maneira:

- fluxo homogêneo: caracterizado pela uniformidade da concentração de sólidos através do eixo vertical do duto. Neste regime, forças turbulentas e outras forças de suspensão superam as forças de gravidade, responsáveis pela deposição do material.

- fluxo heterogêneo: Com a redução da velocidade de escoamento, a intensidade da turbulência e das forças de suspensão diminuem. Como resultado há uma distorção do perfil de concentração de sólidos, com mais sólidos, especialmente partículas grandes, nas partes inferiores do tubo, formando gradientes de granulometria e de concentração de 
sólidos que aumentam com a proximidade da parede inferior do duto. Isto também pode ser chamado fluxo assimétrico.

- fluxo com formação de leito móvel: Este tipo de escoamento acontece em baixas velocidades, quando as partículas tendem a se acumular no fundo do tubo, primeiro na forma de "dunas" separadas até chegar a um leito de movimento contínuo.

- fluxo com formação de leito estacionário: Com a velocidade de escoamento muito reduzida, o leito de partículas do fundo do duto se torna estacionário, e a movimentação das partículas se limita ao topo do leito. Por fim, com a redução continuada da velocidade, o gradiente de pressão aumenta rapidamente e, ao menos que se aplique uma pressão anormalmente alta, acontece o bloqueio do duto.

\subsection{REOLOGIA}

Segundo Nascimento (2008), o conhecimento da reologia em projetos industriais é importante para o projeto dos equipamentos e controle dos processos, e grande parte dos estudos realizados para este fim é feita pela da medição da tensão de cisalhamento $(\tau)$, da taxa de deformação (dV/dy) e da viscosidade do fluido $(\mu)$.

Reologia, por definição, é o estudo da deformação e do escoamento das matérias (BARNES, HUTTON e WATERS, 1993). Basicamente, trata da propensão de um material ao cisalhamento, dada uma taxa de deformação constante (JACOBS, 2005). A resposta geral à taxa de deformação (dV/dy) é o desenvolvimento de uma tensão de cisalhamento $(\tau)$ na direção oposta ao escoamento.

Desta maneira, é razoável dizer que a tensão de cisalhamento é uma função da taxa de deformação do material (JACOBS, 2005):

$$
\tau=f(d V / d y)
$$

A Tabela 1 apresenta os modelos mais importantes para o comportamento dos fluidos. 
Tabela 1 - Modelos matemáticos de comportamento de fluidos.

Tipo de fluido Modelo Equação da Tensão de

\begin{tabular}{lll}
\hline Newtoniano & Newton & $\tau=\mu \frac{d V}{d y}$ \\
Pseudoplástico & Lei de Potência & $\tau=K_{p} \frac{d V^{n}}{d y}$ \\
Bingham & Bingham & $\tau=\tau_{w}+\mu \frac{d V}{d y}$ \\
\hline
\end{tabular}

Fonte: Adaptada de Nascimento (2008).

A tensão de cisalhamento é determinada pelas transformações energéticas durante o escoamento, as perdas por atrito, que causam um gradiente de pressão $(\Delta P)$ entre dois pontos da tubulação (WASP, KENNY e GANDHI, 1977). A diferença de pressão é uma condição imprescindível para que haja movimentação do fluido no tubo.

O gradiente de pressão pode ser determinado, no caso de escoamento laminar, pela viscosidade do fluido $(\mu)$ e as condições do escoamento velocidade (V) diâmetro do tubo (D) em fluidos newtonianos.

$$
\Delta P=\frac{32 \mu V}{D^{2}}
$$

onde:

$$
\begin{aligned}
& \Delta_{P}=\text { Gradiente de pressão; } \\
& \mu=\text { Viscosidade do fluido; } \\
& V=\text { Velocidade de escoamento; e } \\
& D=\text { Diâmetro do tubo. }
\end{aligned}
$$

O gradiente de pressão também pode ser expresso não-dimensionalmente mediante o fator de friç̧ão. Existem diversas equações de fator de fricção, cada uma com seus limitantes (WASP, KENNY e GANDHI, 1977). O mais usado, tanto em escoamento laminar como em turbulento, é o fator de fricção de Fanning, expresso por $(f)$ na Eq. (3): 


$$
f=\frac{\tau_{w}}{\frac{\rho V^{2}}{2}}
$$

onde:

$$
\begin{aligned}
& \tau_{w}=\text { Tensão de cisalhamento na parede do tubo; } \\
& \rho=\text { Densidade do fluido; e } \\
& V=\text { Velocidade de escoamento. }
\end{aligned}
$$

Na Eq. (3) o numerador representa as perdas por fricção e o denominador as forças inerciais.

Estas relações, cabe insistir, valem exclusivamente para os fluidos newtonianos.

Wasp et al. (1977) apontam que um efeito importante da adição de partículas sólidas ao fluido é a alteração da viscosidade. A viscosidade de uma polpa mineral é invariavelmente superior à viscosidade do fluido carreador.

Para fluidos newtonianos, a viscosidade é dada pela relação entre a tensão de cisalhamento e a taxa de deformação, conforme a Eq (4):

$$
\mu=\tau / \frac{d V}{d y}
$$

onde:

$\mu=$ Viscosidade do fluido;

$\tau=$ Tensão de cisalhamento; e

$d V / d y=$ Taxa de deformação.

Para os fluidos dependentes do tempo, como é o caso de muitas polpas minerais, entretanto, a viscosidade não pode ser retratada da mesma maneira. De fato, o uso do próprio termo "viscosidade" é uma questão ainda não resolvida quando se trata de fluidos não newtonianos (WASP, KENNY e GANDHI, 1977). É comum o uso do termo viscosidade aparente nestes casos. Como se pode observar na Figura 3, a viscosidade aparente dos fluidos dependentes do tempo varia de acordo com a taxa de deformação. No caso 
das polpas minerais classificadas como Fluidos de Bingham, quanto maior a taxa de deformação menor a viscosidade aparente.

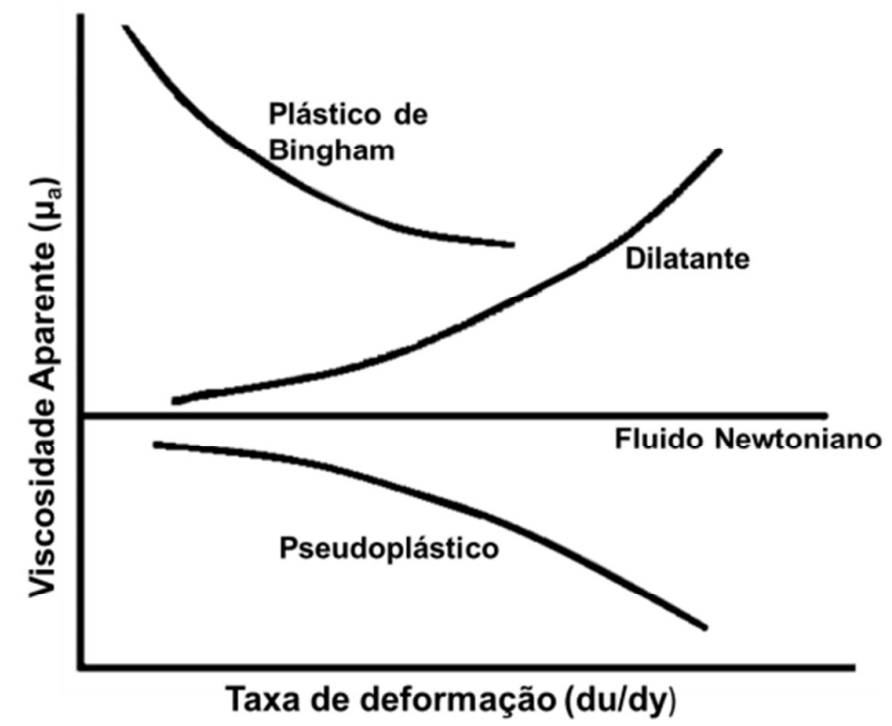

Figura 3 - Viscosidade aparente para fluidos dependente do tempo.

Fonte: Adaptado de Wasp et al. (1977).

Os fluidos de Bingham podem ser categorizados pelo coeficiente de rigidez $(\eta)$ que tem a mesma dimensão da viscosidade (WASP, KENNY e GANDHI, 1977). Para o caso de escoamentos em tubos, é possível definir a "viscosidade efetiva" da polpa mineral $\left(\mu_{e}\right)$ por meio da Eq (5):

$$
\mu_{e}=\frac{\tau_{w}}{8 \frac{V}{D}}
$$

A relação entre a tensão de cisalhamento $(\tau)$ e a taxa de deformação (dV/dy) de um fluido é conhecida como reograma (WILSON, ADDIE, et al., 2006). Para polpas minerais, caracterizadas como fluidos de Bingham, que é um fluido que pode ser chamado de "newtoniano com tensão de escoamento" (GRZINA, ROUDNEV e BURGESS, 2002), a equação matemática do reograma é apresentado pela Eq.(6).

$$
\tau=\tau_{0}+\eta \frac{d V}{d y}
$$

onde:

$\tau=$ Tensão de cisalhamento; 
$\tau_{0}=$ Tensão de escoamento;

$\eta=$ coeficiente de rigidez; $\mathrm{e}$

$\mathrm{dV} / \mathrm{dy}=$ Taxa de deformação.

No entanto, polpas minerais podem não ter comportamento reológico constante (CHHABRA e RICHARDSON, 1999) como os fluidos newtonianos. De fato, como já mencionado anteriormente, elas se comportam como um fluido de Bingham na maioria das vezes, mas a viscosidade aparente muda com a velocidade do escoamento. Por isso, foram criados diversos modelos que pudessem se aproximar do comportamento real desses fluidos. A próxima seção será dedicada a estes modelos.

Como se pode observar pela Eq. (6) e pela Figura 1, polpas minerais precisam de uma tensão inicial maior que zero para que o escoamento se inicie. 0 modelo de Bingham, entretanto é o modelo simplificado do comportamento que se pode esperar de polpas minerais (JACOBS, 2005), pois apesar de considerar a tensão de escoamento maior que zero, simplifica o comportamento por meio de um reograma linear. A Figura 4 foi construída a partir de uma polpa de partículas finas testada no laboratório hidráulico (WILSON, ADDIE, et al., 2006). É possível observar que $\mu$, também chamada de viscosidade secante, definida pela Figura 4, não representa a inclinação do reograma em si. De fato, a inclinação do reograma é representada por $\eta$, 0 coeficiente de rigidez do fluido de Bingham (GRZINA, ROUDNEV e BURGESS, 2002), ou viscosidade tangencial (WILSON, ADDIE, et al., 2006). Também se pode observar que a viscosidade não é constante, mas varia de acordo com $\mathrm{dV} / \mathrm{dy}$. 


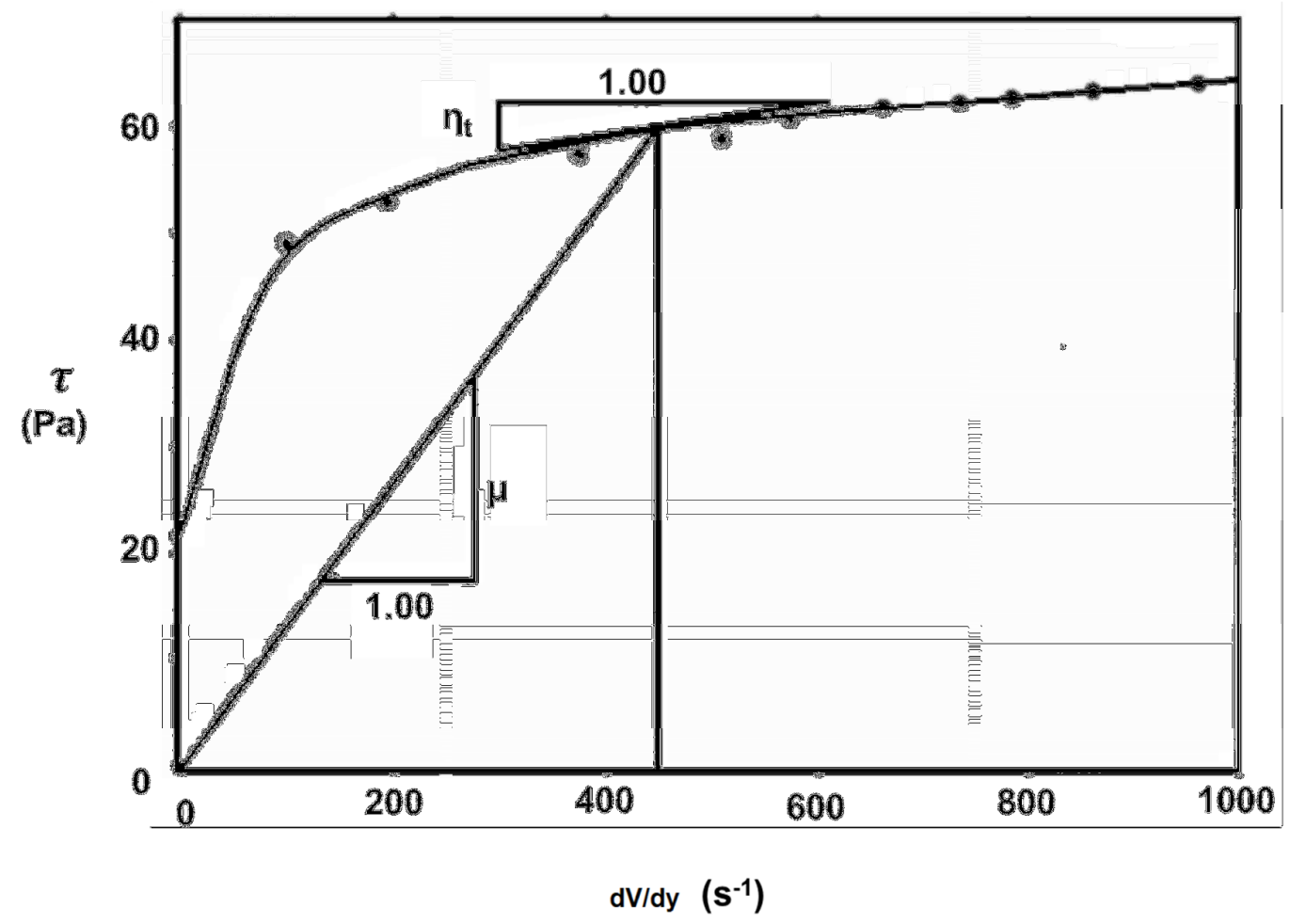

Figura 4 - Exemplo de reograma de polpa mineral.

Fonte: (WILSON, ADDIE, et al., 2006).

Os engenheiros projetistas precisam saber em que momento o escoamento passa a ser completo e predizer a diferença de pressão em termos da velocidade de escoamento (WILSON, ADDIE, et al., 2006).

Quando tratamos de um escoamento laminar de fluido newtoniano, dV/dy na parede do tubo é dada por $\frac{8 \mathrm{~V}}{\mathrm{D}}$, no entanto, para o escoamento de uma polpa como a da Figura 4, tal relação não pode ser aplicada diretamente.

Para chegar ao valor de $\mathrm{V}$ a partir de um fluido de comportamento não newtoniano, é possível seguir os passos propostos por Wilson et al. (2006), descritos na sequência.

O gráfico da Figura 5 representa a anamorfose do reograma da Figura 4. 


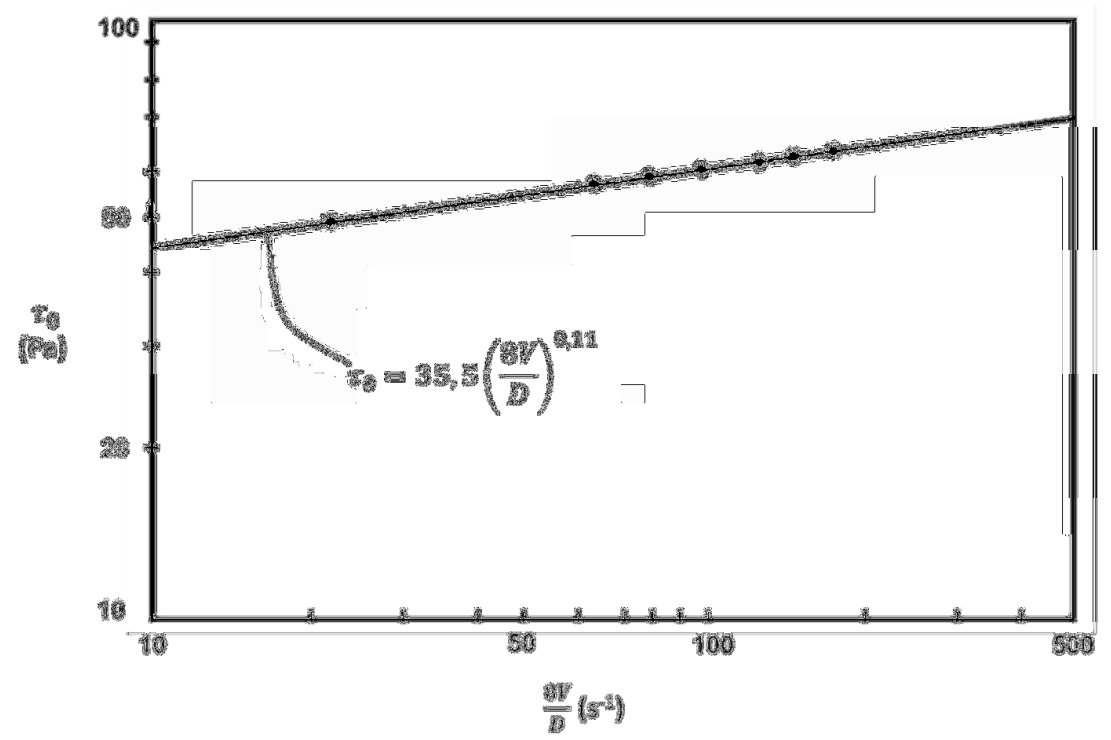

Figura $5-\log \tau_{0}$ versus $\log 8 v / D$.

Fonte: (WILSON, ADDIE, et al., 2006).

A inclinação da reta $(n)$ representa $d \ln \left(\tau_{0}\right) / d \ln (8 V / D)$. Para um fluido não newtoniano que se comporta de acordo com a lei de potência, $n$ é constante.

Polpas minerais com comportamento pseudoplástico podem ser caracterizadas também como fluidos lei de potência, representada pela Eq (7) (ABULNAGA, 2002), (CHAVES, 2012).

$$
\tau_{0}=k\left(\frac{d V}{d y}\right)^{n}
$$

onde:

$$
\begin{aligned}
& \mathrm{K}=\text { coeficiente da lei de potência }\left(\mathrm{Pa} \cdot \mathrm{s}^{\mathrm{n}}\right) ; \mathrm{e} \\
& \mathrm{n}=\text { Índice de comportamento da lei de potência. }
\end{aligned}
$$

\subsection{REGIME DE ESCOAMENTO}

Para a maioria dos fluidos, incluindo as polpas minerais, o regime de escoamento pode ser descrito por dois adimensionais, que são o número de Reynolds e o número de Froude (CHHABRA e RICHARDSON, 1999). O número de Reynolds $(\mathrm{Re})$ representa a razão entre as forças inerciais e as forças viscosas presentes no escoamento, enquanto o número de Froude (Fr) é a razão entre as forças inerciais e as gravitacionais, e indica a estabilidade do 
escoamento. Quando tratamos de uma polpa mineral, o número de Reynolds pode ser descrito pela Eq (8):

$$
R e=\frac{\rho_{p} V D}{\mu_{b}}
$$

onde:

$$
\begin{aligned}
& \mathrm{V}=\text { Velocidade de escoamento }(\mathrm{m} / \mathrm{s}) \\
& \mathrm{D}=\text { Diâmetro do tubo }(\mathrm{m}) \\
& \mu_{b}=\text { Viscosidade plástica }(\mathrm{Pa}) ; \mathrm{e} \\
& \rho_{p}=\text { Densidade da polpa }\left(\mathrm{Kg} / \mathrm{m}^{3}\right) .
\end{aligned}
$$

Para o bom desenvolvimento do escoamento de polpas minerais é, em geral, necessário um regime turbulento, que seja capaz de manter em suspensão as partículas, ou seja, as forças gravitacionais exercidas nas partículas da polpa mineral devem ser menores que as forças inerciais. Abulnaga (2002) recomenda que o escoamento de polpas minerais seja realizado em regime turbulento, com números de Reynolds entre $5 \times 10^{3}$ e não maiores que $10^{8}$.

O número de Froude indica a estabilidade do escoamento da polpa mineral e é descrito pela Eq (9):

$$
F r=\frac{V}{\sqrt{g D}}
$$

onde:

$$
\begin{aligned}
& V=\text { Velocidade de escoamento }(\mathrm{m} / \mathrm{s}) ; \\
& D=\text { Diâmetro do tubo }(\mathrm{m}) ; \mathrm{e} \\
& \mathrm{g}=\text { Aceleração da gravidade }\left(\mathrm{m} / \mathrm{s}^{2}\right)
\end{aligned}
$$

Abulnaga (2002) aponta a necessidade de evitar escoamentos subcríticos, com números de Froude abaixo de 0,8. Escoamentos críticos $(0,8<\mathrm{Fr}<1,5)$ podem ser associados à formação de leitos móveis e têm alta probabilidade de apresentar problemas operacionais. Abulnaga (2002) recomenda operar com Fr>1,5. Já Brown e Heywood (1991) indicam que um número de Froude maior que 1,2 é o suficiente para o escoamento das polpas minerais. 
O número de Froude (Eq (10)) pode ser adaptado ao escoamento de misturas sólido- liquido, levando em consideração, por exemplo, a densidade do sólido e do líquido:

$$
F r=\frac{V}{\sqrt{g D \frac{\rho_{s}-\rho_{l}}{\rho_{l}}}}
$$

onde:

$$
\begin{aligned}
& \rho_{s}=\text { Densidade do sólido }\left(\mathrm{kg} / \mathrm{m}^{3}\right) ; \mathrm{e} \\
& \rho_{l}=\text { Densidade do fluido }\left(\mathrm{kg} / \mathrm{m}^{3}\right) .
\end{aligned}
$$

No dimensionamento de sistemas de escoamento de polpas minerais, a tendência da partícula sólida a depositar ou do fluido conseguir manter a partícula em movimento é o indicador mais importante (TALMON, 2016).

Na prática, esta tendência é baseada na velocidade de deposição da partícula $\left(V_{d}\right)$ e na intensidade da turbulência do escoamento. Wasp et al. (1977) acrescentam que qualquer mecanismo que pretenda descrever 0 comportamento das partículas no escoamento de polpas deve considerar os efeitos das forças inerciais exercidas sobre elas.

A fim de calcular a potência necessária na bomba, além das curvas de eficiência da bomba, é necessário conhecer a energia gasta para a movimentação da polpa em um duto de determinada geometria (CHHABRA e RICHARDSON, 1999). Para isto, é necessário, também, poder calcular as perdas de energia, parâmetro necessário para o dimensionamento do sistema. A perda de carga, ou diferencial de pressão, é uma variável que pode ser medida em ensaios de bombeamento, mas também existem modelos de predição para estes valores.

As perdas por fricção podem ser expressas pela altura manométrica com o uso da equação de Darcy-Weisbach, Eq (11):

$$
H=\frac{f_{D} V^{2} L}{2 g D}
$$

onde:

$$
\mathrm{H}=\text { Altura manométrica }(\mathrm{m}) \text {; }
$$


$\mathrm{L}=$ Comprimento do tubo $(\mathrm{m})$;

$f_{D}=$ Fator de friç̧ão de Darcy;

$\mathrm{D}=$ Diâmetro do tubo $(\mathrm{m}) ; \mathrm{e}$

$\mathrm{V}=$ Velocidade de escoamento $(\mathrm{m} / \mathrm{s})$.

O coeficiente de fricção hidráulico (i) é a razão entre a altura manométrica e o comprimento do tubo, como indicado na Eq (12):

$$
i=\frac{H}{L}=\frac{f_{D} V^{2}}{2 g D}
$$

Considerando as condições possíveis de escoamento de polpa (tubo fechado, escoamento forçado e regime turbulento), o fator de Darcy pode ser calculado pela Eq (13):

$$
f_{D}=\frac{0,25}{\left\{\log _{10}\left[\frac{\varepsilon / D}{3,7}+\left(\frac{5,7}{R e^{0,9}}\right)\right]\right\}^{2}}
$$

onde:

$$
\begin{aligned}
& \varepsilon=\text { Coeficiente de rugosidade do tubo }(\mathrm{m}) ; \mathrm{e} \\
& \mathrm{Re}=\text { número de Reynolds da polpa. }
\end{aligned}
$$

O gradiente de fricção hidráulico é sempre maior para polpas minerais do que para água (ABULNAGA, 2002).

A equação de Darcy-Weisbach pode ser descrita em função do gradiente de pressão (Eq (14)):

$$
i=\frac{f_{D} V^{2}}{2 g D}=\frac{\Delta P}{\rho_{f} g L}
$$

Onde $\Delta P$, expresso e $\mathrm{KPa}$, é a variação de pressão dentro do tubo, também chamado de perda de carga.

A Figura 6 mostra o comportamento típico da perda de carga de uma polpa heterogênea. Altas velocidades fazem com que o perfil de escoamento se torne mais homogêneo e aproxima o comportamento ao de um fluido newtoniano (Ponto A). A partir daí, enquanto a velocidade diminui é possível perceber um distanciamento entre o que antes eram duas retas inclinadas. Nesta região se 
inicia o desenvolvimento do fluxo heterogêneo até chegar ao ponto $B$, a partir de onde se inicia a formação de um leito estacionário de partículas no fundo do tubo. O ponto B, como se pode observar, é o ponto de mínima perda de carga do escoamento da polpa mineral. Isto se dá porque a perda de carga aumenta com a velocidade do escoamento, mas também aumenta à medida que o material se deposita no fundo do tubo graças à redução da área disponível para o escoamento. Uma velocidade acima do ponto B é a situação desejada de escoamento da polpa mineral. Chaves (2012) recomenda o uso da velocidade de escoamento de $0,3 \mathrm{~m} / \mathrm{s}$ a $0,5 \mathrm{~m} / \mathrm{s}$ acima da velocidade do ponto B.

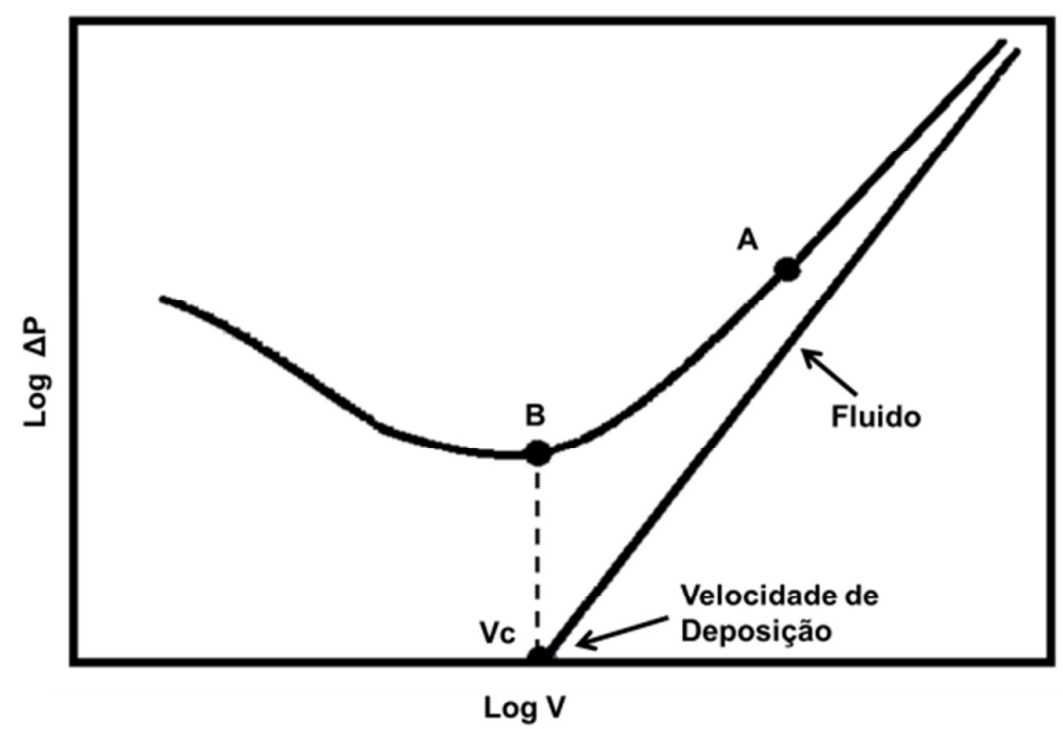

Figura 6 - Perdas de Carga vs Velocidade de escoamento.

Fonte: Adaptado de Wasp et al. (1977).

\subsection{VELOCIDADE DE DEPOSIÇÃO}

Lahiri (2010) define velocidade crítica de escoamento, também chamada de velocidade de deposição, como a velocidade mínima em que se inicia a formação de um leito depositado na parte inferior do duto. É, portanto, a velocidade onde ocorre a passagem do escoamento heterogêneo para o escoamento de leito móvel.

A velocidade de deposição é um parâmetro de grande relevância, já que a acurácia desta variável no momento do projeto permitirá a otimização do sistema, de maneira que o escoamento seja completo, ao mesmo tempo em 
que as perdas energéticas sejam mínimas. A significância deste parâmetro impulsiona os estudos na área, e muitos trabalhos foram realizados para a obtenção de modelos de predição e correlações que permitam o prognóstico em condições diversificadas (OROSKAR e TURIAN, 1980). Entretanto, estas correlações ainda apresentam resultados divergentes entre si, justificando a continuidade desses esforços. Lahiri (2010) aponta que entre os modelos que predizem a velocidade de deposição há, em média, um erro de $25 \%$ comparado com a velocidade de deposição observada.

Durand e Condolios (1952) realizaram um trabalho com areia, material escalpado de densidade média. E chegaram à Eq (15):

$$
V_{d}=F_{l} \sqrt{2 g D\left(\frac{\rho_{s}-\rho_{l}}{\rho_{l}}\right)}
$$

Neste caso, $F_{1}$ é um fator de fricção definido por Durand baseado no tamanho do grão e na concentração volumétrica de sólidos (ABULNAGA, 2002). A Figura 7 é uma representação gráfica do $F_{I}$ proposto por Durand.

O fator de Durand, no entanto, é bastante conservador por levar em consideração somente uma pequena faixa granulométrica enquanto a maioria das polpas é formada por partículas de granulometria variada. Assim sendo, $F_{1}$ foi redefinido por diversos autores (ABULNAGA, 2002). 


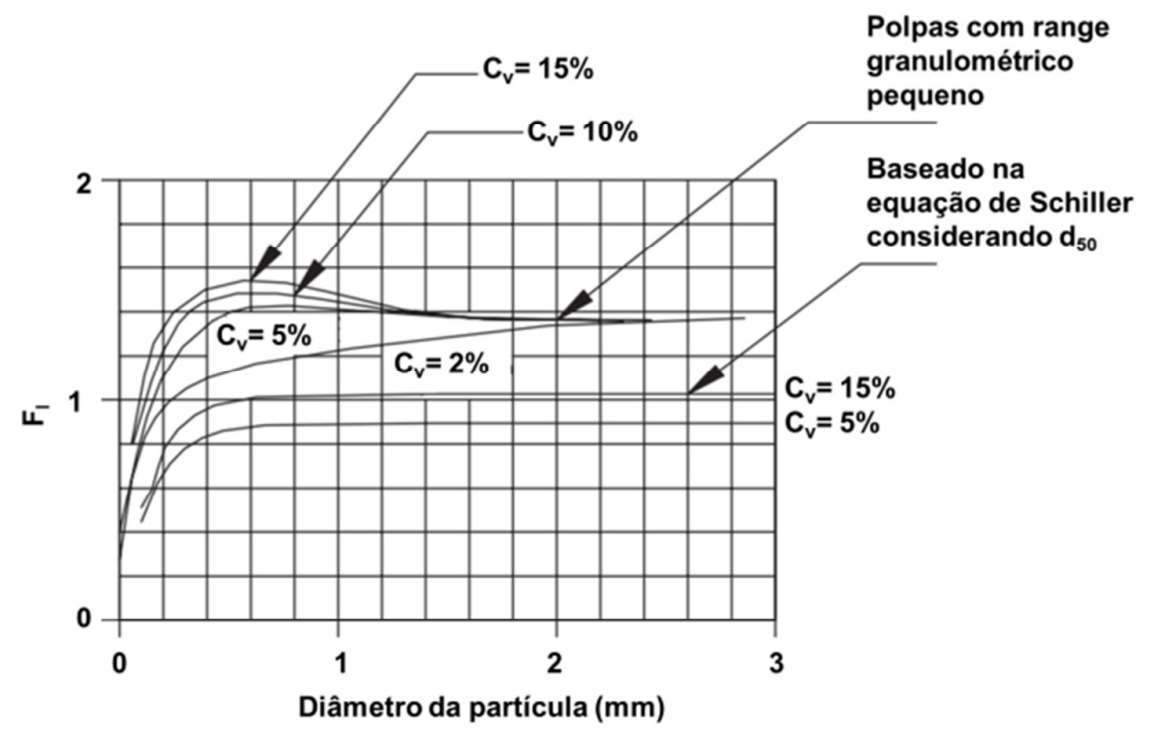

Figura 7 - Fator de Durand.

Fonte: Adaptado de Abulnaga (2002).

O modelo de Wasp leva em consideração que as partículas contidas no escoamento têm o mesmo tamanho. Apesar de ser uma idealização das situações práticas, este modelo pode produzir informações importantes para a predição do comportamento de uma grande gama de polpas minerais.

Segundo Wasp et al. (1977), o modelo foi criado de maneira a melhorar a aderência da $V_{d}$ em polpas de baixa concentração de sólidos $\left(C_{w}=1 \%\right)$, o que pode ser uma limitação prática para sua aplicação.

Wasp et al. (1977) redefiniram $F_{1}$ levando em consideração o diâmetro do tubo, e definiram $V_{d}$ nos termos da $\mathrm{Eq}(16)$ :

$$
V_{d}=4 C_{v}{ }^{1 / 5}\left[2 g D\left(\frac{\rho_{s}-\rho_{l}}{\rho_{l}}\right)\right]^{1 / 2}\left(\frac{d}{D}\right)^{1 / 6}
$$

Wilson et al. (2006) introduziram o conceito de multifases ao escoamento. Eles criaram um modelo de duas camadas para predizer as variáveis do escoamento.

A correlação de Wilson para velocidade de deposição (WILSON, ADDIE, et al., 2006) é calculada por meio da Eq (17):

$$
V d=\left[2 g D\left(\frac{\rho_{s}-\rho_{l}}{\rho_{l}}\right)\right]^{1 / 2}\left(\frac{0,018}{f_{f}}\right)^{0,13}
$$


onde:

$f_{f}=$ fator de fricção do fluido.

Wilson criou um ábaco (Figura 8) para a predição da velocidade de deposição de partículas que operacionaliza o seu próprio modelo (Eq. (17)), muito utilizado para o dimensionamento de sistemas.
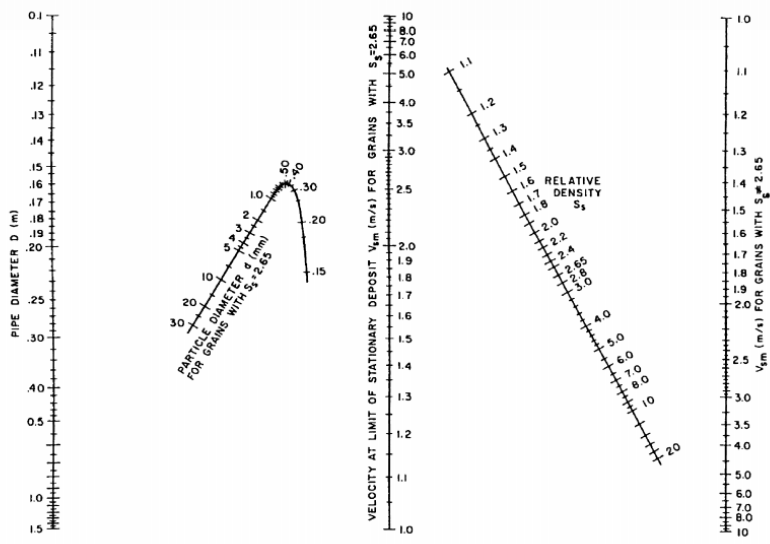

Figura 8 - Ábaco de Wilson para velocidade de deposição de partículas Fonte: (WILSON, ADDIE, et al., 2006).

No modelo de Jacobs (Eq (18)), pode-se observar o uso do coeficiente de arraste como composição das forças atuantes nas partículas.

Correlação de Jacobs para velocidade de deposição (JACOBS, 2005):

$$
V d=3,4\left[g D\left(\frac{\rho_{s}-\rho_{l}}{\rho_{l}}\right)\right]^{1 / 2} C_{d}{ }^{-0,25} C_{v}^{0,33}
$$

onde:

$\mathrm{Cd}=$ Coeficiente de arraste; e

$\mathrm{Cv}=$ Concentração volumétrica de sólidos.

O coeficiente de arraste é um parâmetro que pode ser obtido a partir do conhecimento da velocidade terminal da partícula $\mathrm{V}_{\infty}$. Cd também pode ser expresso em função do número de Reynolds do escoamento, conforme a Eq (19), e indica as forças de fricção atuantes na partícula (WASP, KENNY e GANDHI, 1977). 


$$
C_{d}=\frac{24}{R e}=R e \frac{4 g\left(\rho_{s}-\rho_{l}\right) \mu}{3 \rho^{2} V_{\infty}}
$$

Pinto (2012) utilizou o conceito de esfericidade da partícula para realizar seus modelos e chegar à Eq (20) para a velocidade de deposição:

$$
V d=0,124\left(\frac{\rho_{s}-\rho_{l}}{\rho_{l}}\right)^{1 / 2}\left(\frac{d_{s} \rho_{p} \sqrt{g D}}{\mu_{f}}\right)^{0,37}\left(\frac{d_{s} \Psi}{D}\right)^{-0,007} e^{3,1 C_{v}}
$$

onde:

$$
\begin{aligned}
& \rho_{p}=\text { densidade da polpa; } \\
& \mu_{f}=\text { viscosidade do fluido (água); } \\
& d_{s}=\text { diâmetro médio da partícula (Sauter); e } \\
& \Psi=\text { esfericidade da partícula. }
\end{aligned}
$$

Em seu trabalho, Pinto (2012) mediu a esfericidade da partícula por meio da técnica de permeametria, um ensaio que mede a perda de carga correspondente a uma vazão de ar predeterminada. Mediante esta medida, calculou a porosidade do meio $(\varepsilon)$, definida como a razão entre o volume de espaços vazios pelo volume total do leito (vazio e sólidos), e então, a partir das características do sistema, tais como, porosidade, diâmetro da partícula, perda de carga por altura de leito, viscosidade do fluido e a velocidade média do fluido, usou modelo de Kozeny-Carmam (Eq. (21)) como definição de esfericidade da partícula:

$$
\frac{-\Delta P}{L} \times \frac{\left(\psi D_{p}\right)}{V_{0} \mu} \times \frac{\varepsilon^{2}}{(1-\varepsilon)^{2}}=150
$$

onde:

$$
\begin{aligned}
& \varepsilon=\text { a porosidade do meio; } \\
& D_{P}=\text { diâmetro médio volumétrico; e } \\
& V_{0}=\text { velocidade média do fluido. }
\end{aligned}
$$

\subsection{PERDA DE CARGA}

Desde a fase inicial dos projetos de sistemas de bombeamento é adequado conhecer os efeitos dos sólidos da polpa na perda de carga do escoamento 
para estudos de viabilidade, projetos básicos e estimativas de custos, ou até mesmo para justificar gastos com uma planta piloto (WILSON, ADDIE, et al., 2006).

Existem vários modelos empíricos para a obtenção da perda de carga em transporte hidráulico de sólidos. Estes modelos, entretanto, enfrentam defensores, corretores e até mesmo opositores, de maneira que é recomendável, sempre que possível, recorrer aos ensaios laboratoriais para a obtenção deste parâmetro (BRUM, 2017).

Quando se trata da predição da perda de carga de polpas minerais, a abordagem mais comum é a comparação do coeficiente de gradiente hidráulico da polpa (i) com o do volume equivalente de água ( $\left.\mathrm{i}_{w}\right)$. Lahiri (2010) afirma que i é sempre maior que $i_{w}$.

Um dos primeiros modelos empíricos de correlação de perda de carga foi descrito por Durand e Condolios em 1952 (Eq (22)). Neste estudo, diversas medidas de perda de carga foram feitas em ensaios com misturas de água e areia com partículas de $100 \mu \mathrm{m}$ a $25 \mathrm{~mm}$ e diâmetros de tubos de $3,8 \mathrm{~cm}$ a 58 $\mathrm{cm}$. Foram utilizadas concentrações volumétricas de sólidos $\left(\mathrm{C}_{\mathrm{v}}\right)$ acima de $60 \%$ (DURAND e CONDOLIOS, 1952).

$$
\frac{i-i_{w}}{i_{w} C_{v}}=k\left[\frac{V^{2}}{g D} \sqrt{C_{d}}\right]^{-1,5}
$$

onde:

$$
\begin{aligned}
& i=\text { coeficiente de gradiente hidráulico da polpa (-); } \\
& i_{w}=\text { coeficiente de gradiente hidráulico da água }(-) ; \\
& C_{v}=\text { concentração volumétrica de sólidos }(\%) ; \\
& k=\text { constante definida por Durand em } 176 ; \\
& V=\text { velocidade do escoamento }(\mathrm{m} / \mathrm{s}) ; \\
& g=\text { aceleração da gravidade }\left(\mathrm{m} / \mathrm{s}^{2}\right) ; \\
& D=\text { diâmetro interno do tubo }(\mathrm{m}) ; \text { e } \\
& C_{d}=\text { coeficiente de arraste. }
\end{aligned}
$$


Foi criado o adimensional Z, demonstrado na Eq (23), para representar a interferência dos sólidos na perda de carga.

$$
Z=\frac{i-i_{w}}{i_{w} C_{v}}
$$

Onde o gradiente hidráulico da água pode ser calculado pela Eq (24):

$$
i_{w}=\frac{f_{D} V^{2}}{2 g D}
$$

O modelo de Wasp et al. (1977) considera que a perda de carga é uma soma da perda de carga resultante da fase homogênea do escoamento e do excesso de perda de carga necessária para a turbulência. O modelo de "duas camadas" é a somatória da perda de carga calculada na fase homogênea com a perda de carga calculada na fase heterogênea (DIBAKAR e ROUTRAY, 2015).

$$
\frac{i-i_{w}}{i_{w} C_{v}}=K\left[\left(\frac{V^{2}}{g D}\right)\left(\frac{\rho_{l}}{\rho_{s}-\rho_{l}}\right) \sqrt{C_{d}}\right]^{-1,5}
$$

Onde K é uma constante definida por Wasp et al. (1977) que pode variar de 80 a 150.

A evolução do modelo de Durand para o modelo de Wasp consiste, além da determinação do cálculo da perda de carga para duas camadas diferentes do escoamento, na inclusão das variáveis densidade do sólido e do fluido, o que acrescenta ao cálculo uma distinção entre escoamentos de diferentes polpas minerais.

Newitt et al. (1955) basearam seus estudos na velocidade terminal da partícula $\left(\mathrm{V}_{\infty}\right)$ com o objetivo de determinar a perda de carga (SILVA et al., 2015). O modelo de Newitt é apresentado na Eq (26).

$$
\frac{i-i_{w}}{i_{w} C_{v}}=k_{2}\left[\frac{\rho_{s-} \rho_{l}}{\rho_{l}}\right]\left[\frac{g D V_{\infty}}{V_{m}^{3}}\right]
$$

Onde $\mathrm{K}_{2}$ é uma constante determinada em 1100.

A vantagem do modelo de Newitt é que a determinação da velocidade terminal da partícula pode ser feita diretamente em laboratório, ao passo que os métodos de obtenção do coeficiente de arraste utilizado nos modelos 
anteriores requerem cálculos que podem conter erros e diminuem a efetividade do modelo.

Já o modelo de Miedema (2015) leva em consideração que, em um fluxo heterogêneo, cada camada tem suas especificidades e deve ser considerada separadamente.

$$
\frac{i-i_{w}}{i_{w} C_{v}}=\frac{V_{\infty}\left(1-\frac{c_{v}}{K_{c}}\right)}{V}+7,5^{2}\left(\frac{1}{F_{D}}\right)\left(\frac{V_{\infty}}{\sqrt{g D}}\right)^{8 / 3}\left(\frac{(v g)^{1 / 3}}{V}\right)^{2}
$$

onde:

$$
\begin{aligned}
& v=\text { viscosidade cinemática }\left(\mathrm{m}^{2} / \mathrm{s}\right) ; \mathrm{e} \\
& \mathrm{Kc}=\text { constante de distribuição de concentração (menor que 1). }
\end{aligned}
$$

A adição de várias camadas de escoamento, cada uma com comportamento diferente, demonstra a tendência de especificar o fluxo em diversas partes, culminando em modelos que usam a tecnologia Computational Fluid Dynamics (CFD), que podem levar em consideração o movimento e as forças aplicadas em três dimensões, escoamento em multifases, ajustar modelos computacionais capazes de prever o comportamento das polpas em determinadas bombas e outros.

Apesar dos avanços no campo dos modelos de diagnósticos de perda de carga para polpas de minério, a correlação entre estes resultados e os valores medidos está sujeita a incertezas. A maioria dos modelos de predição de perda de carga estão baseados em situações de escoamento limitadas, seja em granulometria (materiais muito uniformes) ou pelas concentrações de sólidos (muito baixas ou moderadas) (LAHIRI, 2010).

De fato, em seu livro, Chaves (2012) cita modelos de predição da perda de carga, mas indica o uso de ábacos e catálogos de bombas para realizar os exercícios de dimensionamento dos sistemas. 


\section{MATERIAIS E MÉTODOS}

Nesta seção são detalhados os materiais e os procedimentos que foram utilizados para a obtenção dos resultados necessários. Os ensaios foram realizados com três materiais diferentes, carbonatito, areia e minério de ferro.

\subsection{MATERIAIS}

\subsubsection{Amostras de minerais}

As amostras utilizadas foram recebidas da Valefertil (carbonatito), da Vale (minério de ferro) e da Pedreira Maria Teresa (areia).

O minério de ferro recebido da Vale provém da Mina do Pico, localizada em Nova Lima, (MG). A amostra consiste em um concentrado convencional de pellet feed - material fino utilizado na fabricação de pelotas.

A areia foi coletada no Porto de Areia Branca, de propriedade da Pedreira Maria Teresa, localizado em São Bernardo do Campo (SP). Foi feita amostragem de areia grossa diretamente da pilha de produto.

O carbonatito foi retirado da Valefertil, da Mina de Cajati, localizada em Cajati (SP). A amostra corresponde a um subproduto da mina de fosfato, um calcário que tem como fim a produção de cimento.

Todas as amostras foram utilizadas para a composição de polpas com concentração mássica de sólidos de 15\%, 30\% e 50\%.

\subsubsection{Equipamentos}

\subsubsection{Circuitos de bombeamento}

Os ensaios foram realizados em duas unidades de bombeamento. A primeira de 2" $(50,8 \mathrm{~cm})$ de diâmetro ilustrada na Figura 9 e a segunda, de 3 " $(76,2 \mathrm{~cm})$ e 4" (101,6 cm), ilustrada na Figura 10. 


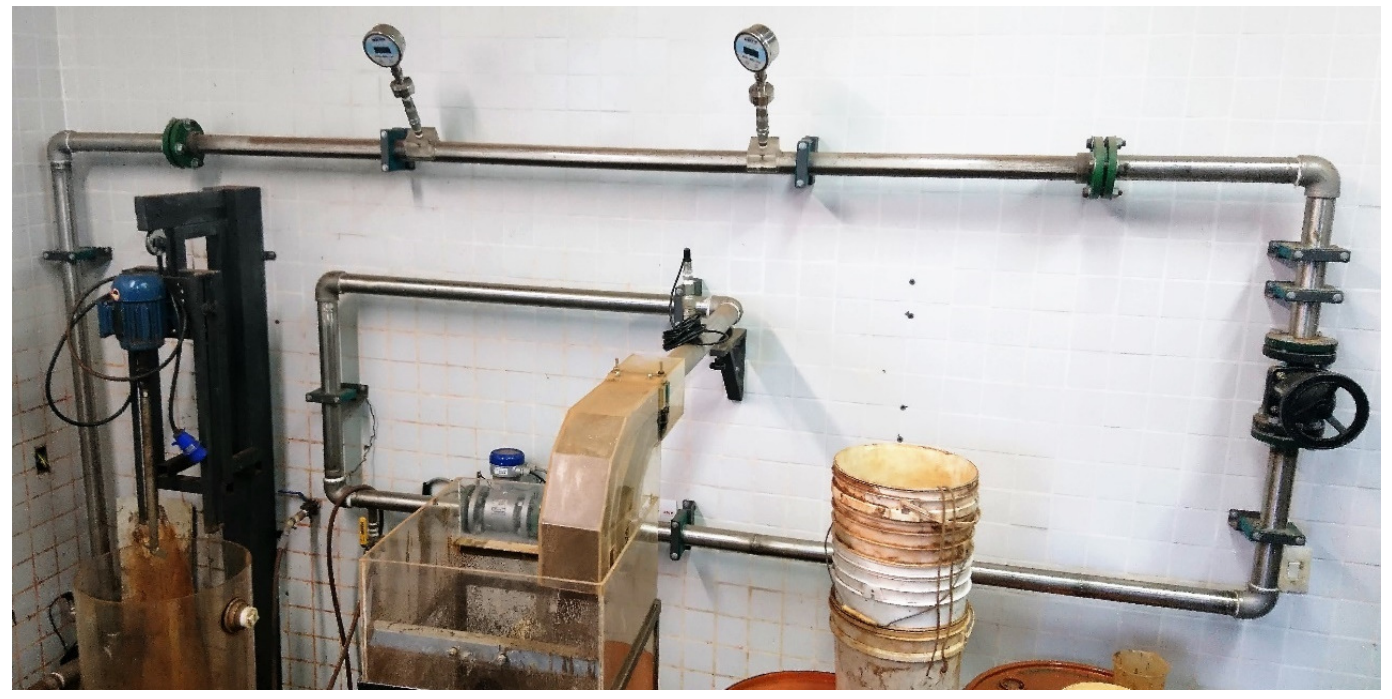

Figura 9 - Test loop de bombeamento de 2"

Fonte: Elaborada pela autora

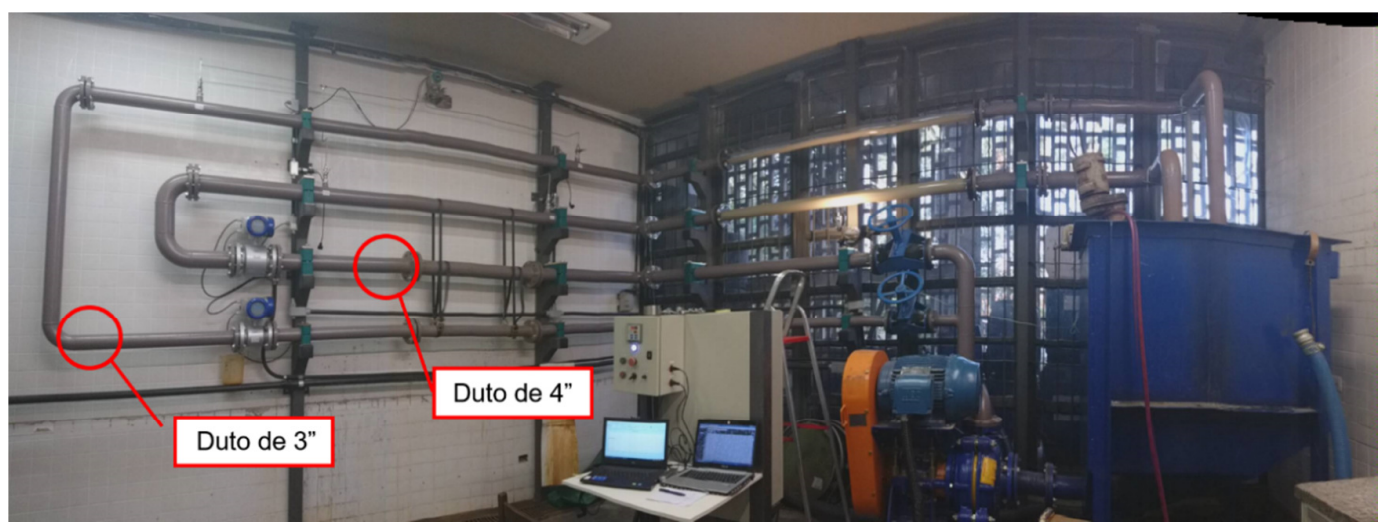

Figura 10 - Test loop de bombeamento de 3" e 4"

Fonte: Elaborada pela autora.

A unidade de bombeamento de 2" conta com uma caixa de bomba com agitador acionado por um motor WEG de 750 W de potência. Já o sistema de 3" e 4" tem uma caixa de bomba de fundo chanfrado de 1,2 $\mathrm{m}^{3}$. Um misturador portátil foi instalado durante os ensaios para melhorar as condições de homogeneidade da polpa durante os ensaios, como na Figura 11. 


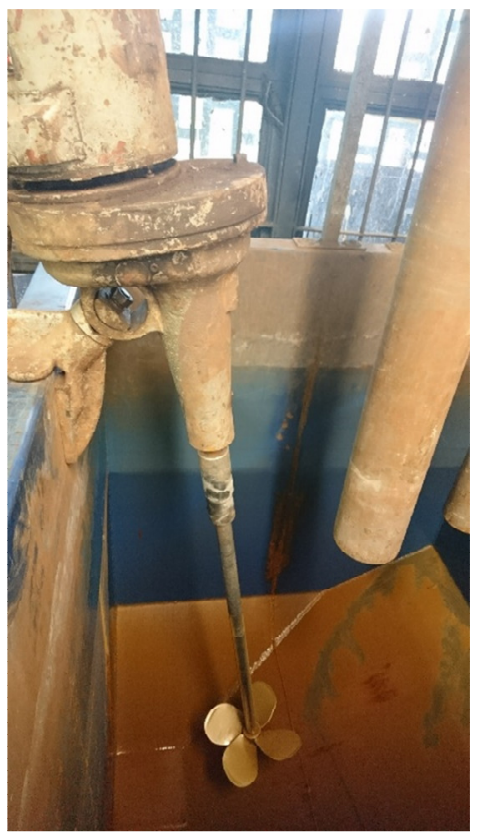

Figura 11 - Misturador do sistema de 3" e 4"

Fonte: elaborada pela autora.

As duas unidades de testes estão equipadas com um trecho de tubo transparente para determinação visual da velocidade de deposição das partículas conforme Figura 12.

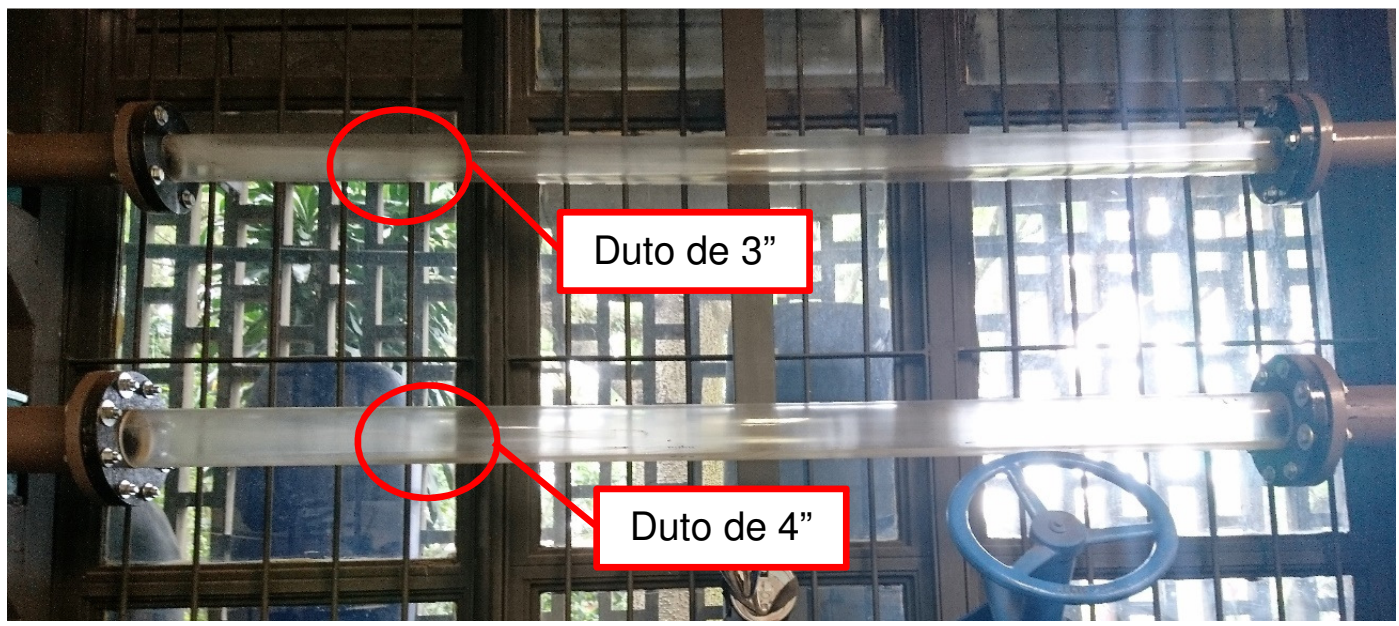

Figura 12 - Trecho de tubulação transparente na unidade de 3" e 4"

Fonte: elaborada pela autora.

A bomba da unidade de 2" é uma bomba centrífuga para polpa da Marca IMBIL, com 5 Cv de potência e a unidade de 3" e 4" conta com uma bomba centrífuga de eixo horizontal da marca Weir Minerals, modelo WARMAN 4/3CAH A05/A05 WRT MS com motor acoplado de $30 \mathrm{Cv}$. 
O test loop de 2" é equipado com dois medidores de pressão. Já o sistema de 3 " e 4" conta com um medidor diferencial de pressão conectado a dois pontos

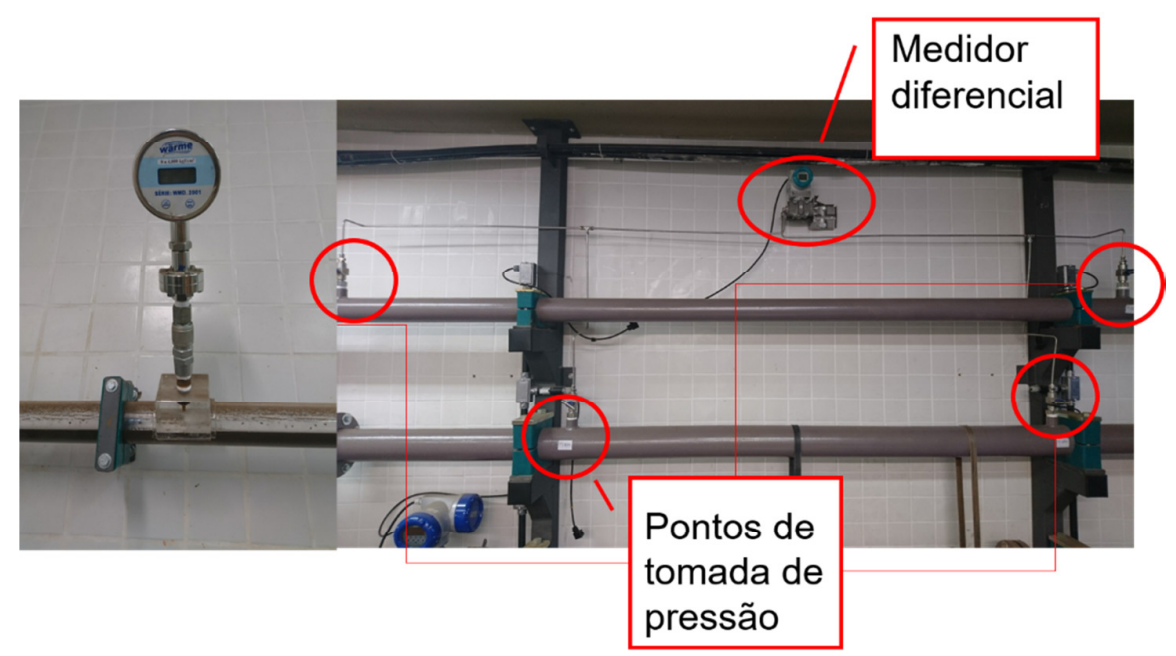

Figura 13 - Medidores de pressão dos loops

do duto de 3" e a dois pontos do duto de 4", conforme Figura 13.

Fonte: Elaborado pela autora.

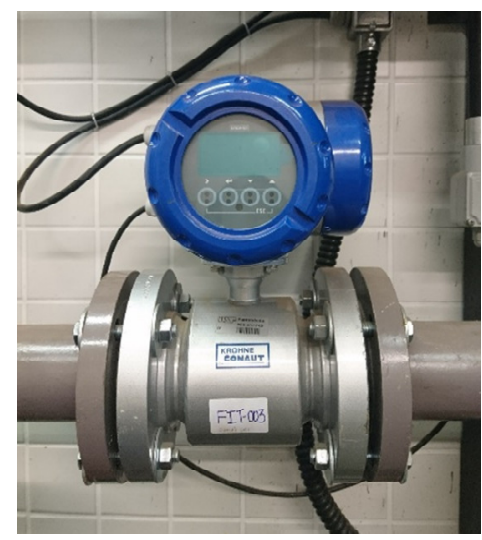

Figura 14 - Medidor de vazão e velocidade de escoamento

Fonte: Elaborado pela autora.

A medida da vazão mássica de escoamento foi feita com o uso de medidores de velocidade e vazão magnéticos.Ambos os circuitos contam com inversores de frequência acoplados ao motor da bomba, para o controle da rotação e, consequentemente, da velocidade de escoamento. O circuito de 2", além do inversor do motor da bomba, conta também com um inversor acoplado ao agitador. 
Para o direcionamento do fluxo no circuito de 3" e 4" foram instaladas válvulas mangote do tipo corpo aberto. Também foi acoplado um sistema de aquisição de dados PRESYS modelo VR-2000-3.3.

\subsection{MÉTODOS}

\subsubsection{Planejamento de ensaios}

A Tabela 2 apresenta os ensaios que foram realizados para o trabalho. Cada material testado (minério de ferro, carbonatito e areia) foi caracterizada, testada no loop de 3" e 4" e ensaiada no loop de 2".

\begin{tabular}{|c|c|c|}
\hline \multicolumn{3}{|c|}{ Caracerização dos materiais } \\
\hline $\begin{array}{c}\text { Análise } \\
\text { granulométrica }\end{array}$ & Mineralogia & $\begin{array}{l}\text { Determinação do } \\
\text { peso específico }\end{array}$ \\
\hline \multicolumn{3}{|c|}{ Ensaios de bombeamento no sistema de 3" e 4" } \\
\hline $\begin{array}{l}\text { Concentração } \\
\text { mássica 15\% }\end{array}$ & $\begin{array}{l}\text { Concentração } \\
\text { mássica 30\% }\end{array}$ & $\begin{array}{l}\text { Concentração } \\
\text { mássica 50\% }\end{array}$ \\
\hline \multicolumn{3}{|c|}{ Ensaios de bombeamento no sistema de 2} \\
\hline $\begin{array}{l}\text { Concentração } \\
\text { mássica 15\% }\end{array}$ & $\begin{array}{l}\text { Concentração } \\
\text { mássica 30\% }\end{array}$ & $\begin{array}{l}\text { Concentração } \\
\text { mássica 50\% }\end{array}$ \\
\hline
\end{tabular}

Tabela 2 - Ensaios realizados

Fonte: Elaborada pela autora.

\subsubsection{Análise das amostras}

As amostras de minério recebidas foram analisadas para a obtenção dos seguintes parâmetros: distribuição granulométrica, densidade do sólido e análise mineralógica.

A análise granulométrica foi feita por meio de peneiramento a seco em laboratório. Para o minério de ferro, constituído principalmente por material fino 
(abaixo de 200\#), foi feito também um ensaio no cyclosizer. A partir da curva granulométrica foram definidos os parâmetros de tamanho de grãos $d_{10}, d_{50}, d_{60}$ e d d95 de cada material.

O peso específico do sólido foi obtido com o uso de picnômetro mediante a Eq (29):

$$
\rho_{s}=\frac{A_{2}-A_{1}}{\left(A_{4}-A_{2}\right)-\left(A_{1}-A_{3}\right)}
$$

onde:

$$
\begin{aligned}
& A_{1}=\text { massa do picnômetro; } \\
& A_{2}=\text { massa do picnômetro + amostra; } \\
& A_{3}=\text { massa do picnômetro + amostra + água; } \\
& A_{4}=\text { massa do picnômetro + água. }
\end{aligned}
$$

Os minerais presentes nas amostras foram determinados por difratometria de raios $\mathrm{X}$.

\subsubsection{Preparação das polpas minerais}

Foram calculadas as massas de água e de sólidos para cada batelada de ensaios, de acordo com o volume dos tanques, para atingir as concentrações de sólidos pré-determinadas de 15\%, 30\% e 50\%.

A concentração de sólidos é determinada pela Eq (30):

$$
C_{w}=\frac{m_{s}}{m_{p}} .100
$$

onde:

$$
\begin{aligned}
& \mathrm{C}_{\mathrm{w}}=\text { concentração mássica de sólidos }(\%) ; \\
& \mathrm{m}_{\mathrm{s}}=\text { massa de sólido }(\mathrm{kg}) ; \mathrm{e} \\
& \mathrm{mp}=\text { massa de polpa }(\mathrm{kg}) .
\end{aligned}
$$

Também foi determinada a densidade da polpa, que será calculada da seguinte maneira: 


$$
\rho_{p}=\frac{100}{\frac{C_{w}}{\rho_{s}}+\frac{100-C_{w}}{\rho_{l}}}
$$

onde:

$$
\begin{aligned}
& \text { Cw = concentração mássica de sólidos }(\%) \\
& \rho_{\mathrm{p}}=\text { densidade da polpa mineral }\left(\mathrm{kg} / \mathrm{m}^{3}\right) \\
& \rho_{\mathrm{s}}=\text { densidade do sólido }\left(\mathrm{kg} / \mathrm{m}^{3}\right) \\
& \rho_{\mathrm{f}}=\text { densidade do fluido }\left(\mathrm{kg} / \mathrm{m}^{3}\right)
\end{aligned}
$$

\subsubsection{Ensaio de bombeamento}

O objetivo dos ensaios de bombeamento é a determinação de valores de Vd e da mínima perda de carga do escoamento, estabelecidos com o auxílio da curva $\mathrm{V}$ vs $\Delta \mathrm{P}$.

O escoamento foi sempre iniciado em uma velocidade alta, na qual todas as partículas estavam em suspensão e, com o auxílio do inversor de potência, diminuiu-se a rotação da bomba até o ponto em que se verificou o início da deposição de partículas no fundo do tubo transparente, formando um escoamento com leito fixo. Este monitoramento foi visual conforme exemplificado na Figura 15.

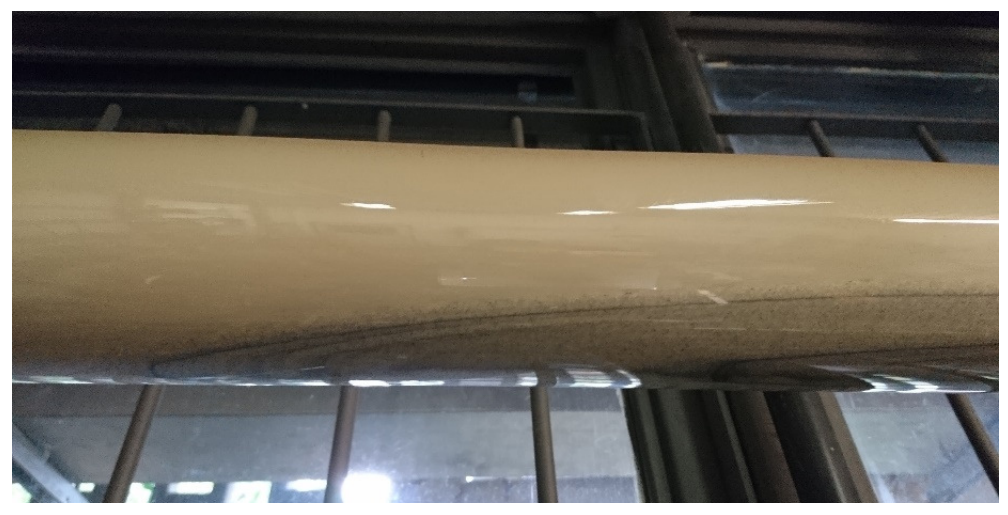

Figura 15 - Exemplo de escoamento com leito fixo

Fonte: Elaborada pela autora.

Atingido este ponto de velocidade de deposição para o escoamento, o ensaio foi completado. 
A velocidade de deposição é o ponto de mínima perda de carga, conforme apresentado na Figura 6.

A perda de carga é o resultado das tomadas de pressão feitas no circuito de 2" e no circuito de 3 " e 4".

Várias dificuldades foram encontradas durante a realização dos ensaios:

- Impossibilidade de trabalhar com a areia nas concentrações de $30 \%$ e $50 \%$ de sólidos.

- Impossibilidade de identificação visual da formação de leito fixo no escoamento de minério de ferro.

- Deposição de sólidos na caixa de bombas com todas as amostras. Parte dos ensaios precisou ser refeita. 


\section{ANÁLISE E DISCUSSÃO DOS RESULTADOS}

\subsection{CARACTERIZAÇÃO DOS MATERIAIS}

\subsubsection{Análise mineralógica dos materiais}

A caracterização mineralógica do minério de ferro foi feita pelo Laboratório de Tratamento de Minérios (LTM) do próprio Departamento de Engenharia de Minas e de Petróleo da EPUSP. Já o carbonatito e a areia foram enviados ao Laboratório de Uso e Manejo do Território e dos Recursos Naturais da Universidade de Passo Fundo, sob a orientação do prof. Edson Bortoluzzi, para a coleta dos padrões difratométricos.

Os resultados indicaram uma areia composta principalmente por quartzo, muscovita e biotita. Já o rejeito de apatita é formado por calcita e traços de dolomita. Por fim, o minério de ferro é composto de goethita, hematita e quartzo.

As Figura 16, Figura 17 e Figura 18 apresentam, respectivamente, os difratogramas obtidos nas análises de areia, carbonatito e minério de ferro.

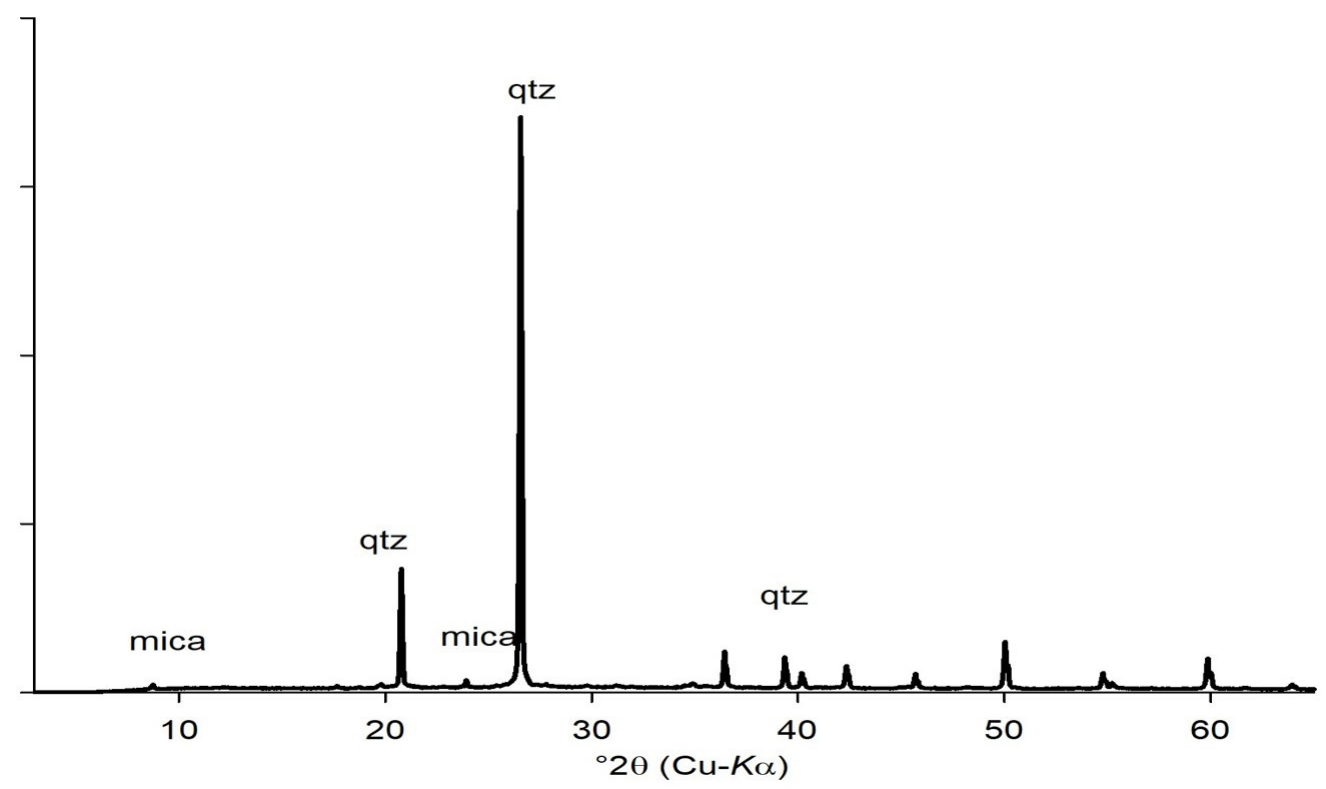

Figura 16 - Difratograma da areia 


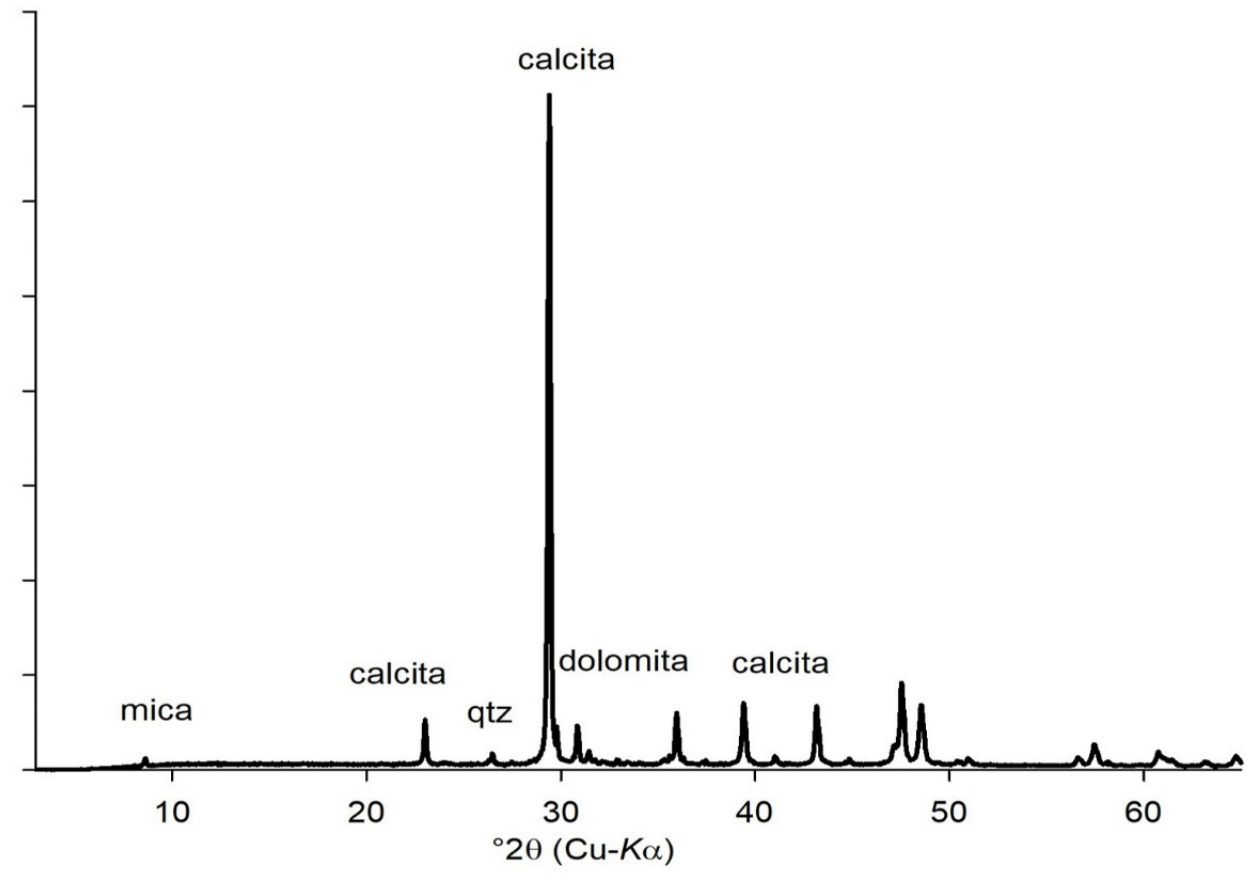

Figura 17- Difratograma do carbonatito

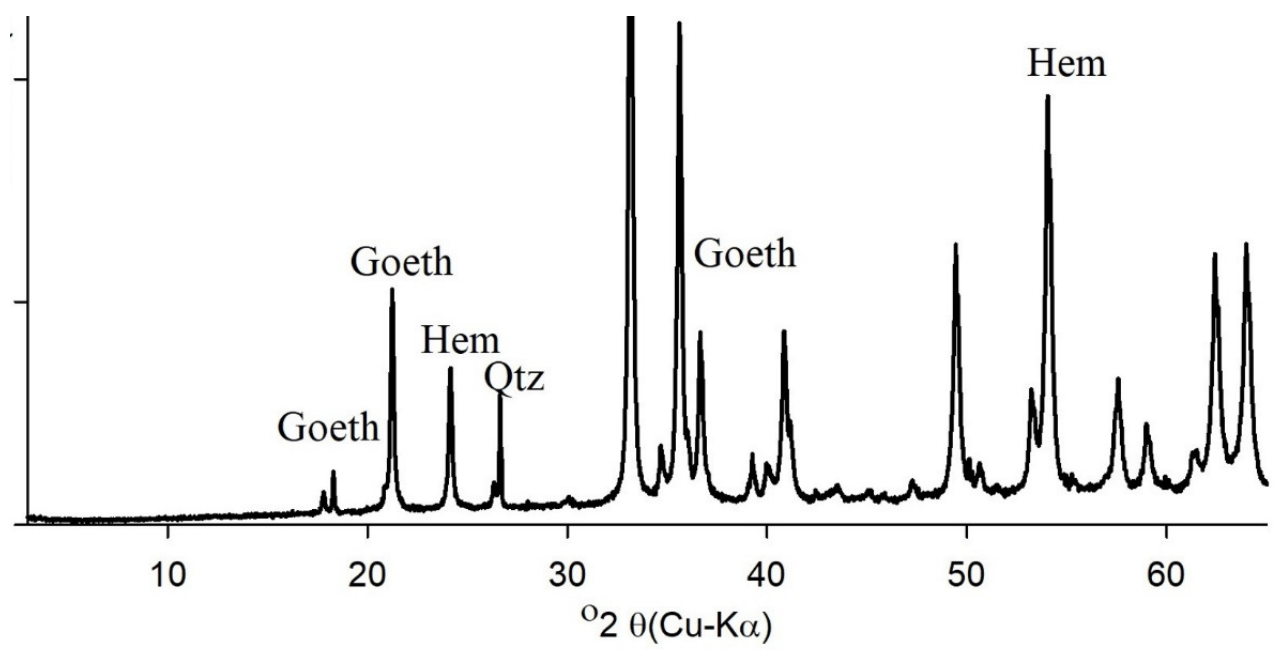

Figura 18- Difratograma do minério de ferro

\subsubsection{Análise granulométrica dos materiais}

A análise granulométrica foi feita por peneiramento a seco em laboratório. Como o minério de ferro é formado principalmente por partículas muito finas, ou seja, menores que 200\# $(0,074 \mathrm{~mm})$, foi necessária uma medida adicional 
para maior conhecimento da fração fina, por isso esta parte muito fina do material foi testada no cyclosizer.

A granulometria expôs diferenças entre os minérios. A areia é o material mais grosso, com intervalo granulométrico variando entre $0,015 \mathrm{~mm}$ e $4,8 \mathrm{~mm}$. $O$ carbonatito variou entre $0,035 \mathrm{~mm}$ e $2 \mathrm{~mm}$ e o minério de ferro, o mais fino de todos, variou entre $0,0085 \mathrm{~mm}$ e $0,04 \mathrm{~mm}$.

A granulometria do material é uma variável que interfere de maneira significativa na operação de bombeamento, a ponto de, por exemplo, ter inviabilizado o bombeamento da areia em concentrações altas, por ser um material muito grosso.

Pode-se observar as curvas granulométricas dos materiais ensaiados na Figura 19.

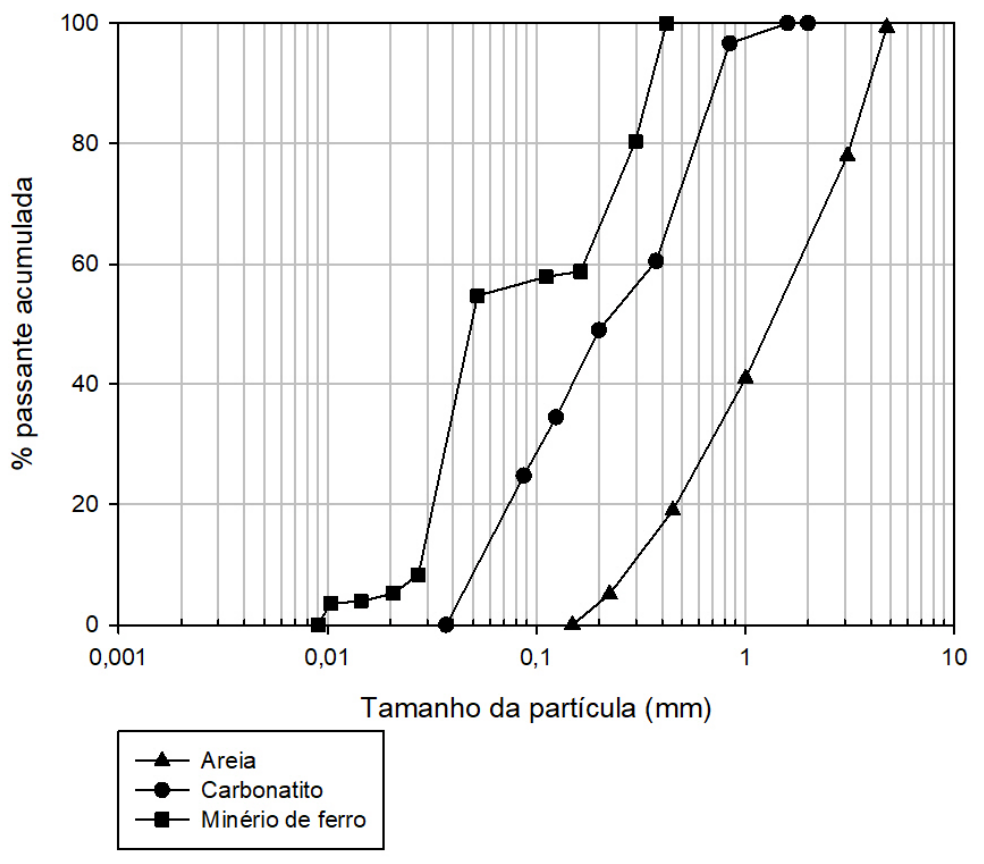

Figura 19 - Curvas granulométricas dos materiais testados 
Os parâmetros que são utilizados nos modelos de predição, o $d_{10}, d_{50}$ e $d_{95}$, estão relacionados na Tabela 3 . Também foi calculado o coeficiente de uniformidade da polpa, definido por Durand e Condolios (CHAVES, 2012) como $\mathrm{CU}=\mathrm{d}_{60} / \mathrm{d}_{10}$. Segundo esta definição, a amostra é muito uniforme quando $\mathrm{CU}<5$, uniforme se $5 \leq \mathrm{CU}<15$ e não uniforme para $\mathrm{CU} \geq 15$.

Tabela 3 - Parâmetros de granulometria

\begin{tabular}{lccccc}
\hline & $\mathbf{d}_{10}(\mathbf{m m})$ & $\mathbf{d}_{50}(\mathbf{m m})$ & $\mathbf{d}_{60}(\mathbf{m m})$ & $\mathbf{d}_{95}(\mathbf{m m})$ & $\mathbf{C U}$ \\
\hline Areia & 0,280 & 1,400 & 2,00 & 4,500 & Uniforme \\
Minério de & 0,029 & 0,050 & 0,07 & 0,400 & Muito \\
ferro & 0,050 & 0,200 & 0,40 & 0,730 & Uniforme \\
Carbonatito & $0,00 r m e$ \\
\hline
\end{tabular}

\subsubsection{Ensaios de densidade}

A densidade foi um dos critérios utilizados para a escolha dos materiais para o trabalho. O minério de ferro apresentou densidade maior que os outros materiais.

A Tabela 4 apresenta os resultados dos ensaios de picnometria.

Tabela 4 - Densidades dos materiais e das polpas minerais

\begin{tabular}{lcrcc}
\hline & & \multicolumn{3}{c}{$\boldsymbol{\rho}_{\mathrm{p}}\left(\mathbf{g} / \mathbf{c m}^{3}\right)$} \\
\cline { 3 - 5 } Material & $\boldsymbol{\rho}_{\mathbf{s}}$ & $\mathbf{C}_{\mathrm{w}}$ & $\mathbf{C}_{\mathrm{w}}$ & $\mathbf{C}_{\mathrm{w}}$ \\
& $\left(\mathbf{g} / \mathbf{c m}^{3}\right)$ & $\begin{array}{r}\mathbf{1 5 \%} \\
\text { Areia }\end{array}$ & $\mathbf{3 0 \%}$ & $\mathbf{5 0 \%}$ \\
\hline Ferro & 2,80 & 1,27 & - & - \\
Carbonatito & 2,54 & 1,53 & 2,24 & 2,95 \\
\hline
\end{tabular}

\subsection{ENSAIOS DE BOMBEAMENTO}

A areia testada gerou resultados somente para a concentração de sólidos mais baixa. Já era esperado um alto grau de dificuldade no bombeamento deste material, uma vez que a granulometria é bastante grossa. Chaves (2012) recomenda o uso de bombas de cascalho e areia para materiais como este, e não o de bombas de polpa, como é o caso das bombas existentes nas instalações utilizadas. 
Quando o sistema foi alimentado com a polpa de areia com Cw 30\%, o escoamento não se desenvolveu completamente, e os dutos ficaram obstruídos pelo material. A desobstrução dos tubos só foi possível com a desmontagem e lavagem da tubulação. A Figura 20 mostra as consequências do entupimento do tubo. O material sedimentado foi compactado pela pressão exercida pela bomba e teve que ser retirado manualmente. A experiência do entupimento do tubo elucida muito bem os riscos de um escoamento indevido.

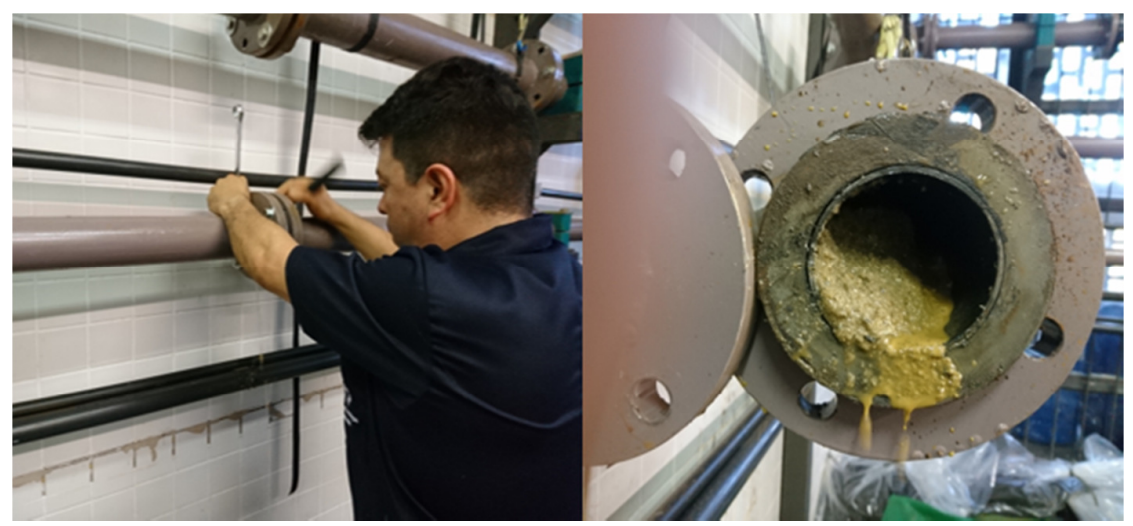

Figura 20 - Desmontagem do duto entupido com polpa de areia

Os ensaios de areia a Cw $15 \%$ resultaram nas curvas $V_{c} X \Delta P$ apresentadas na ¡Error! No se encuentra el origen de la referencia..

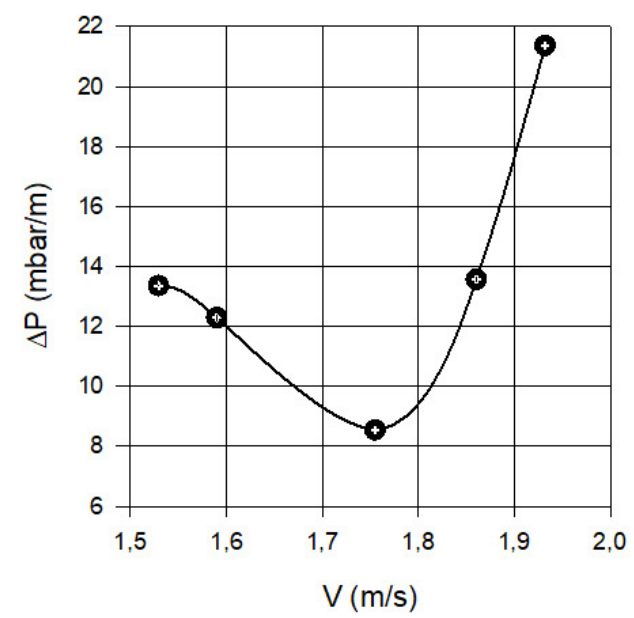

(a) Areia a $15 \%$ em tubo de $2 "$

Figura 21 - Curvas $\mathrm{V} X \Delta \mathrm{P}$ para areia a $15 \%$ (continua) 


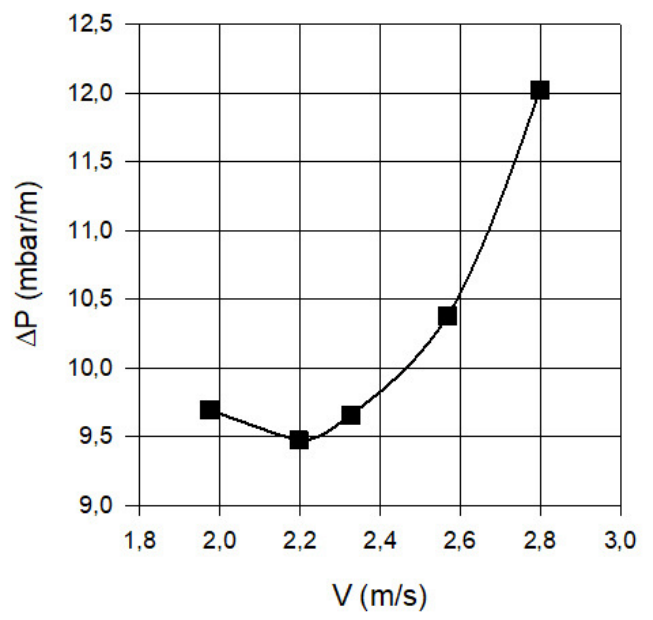

(b) Areia a 15\% em tubo de 3"

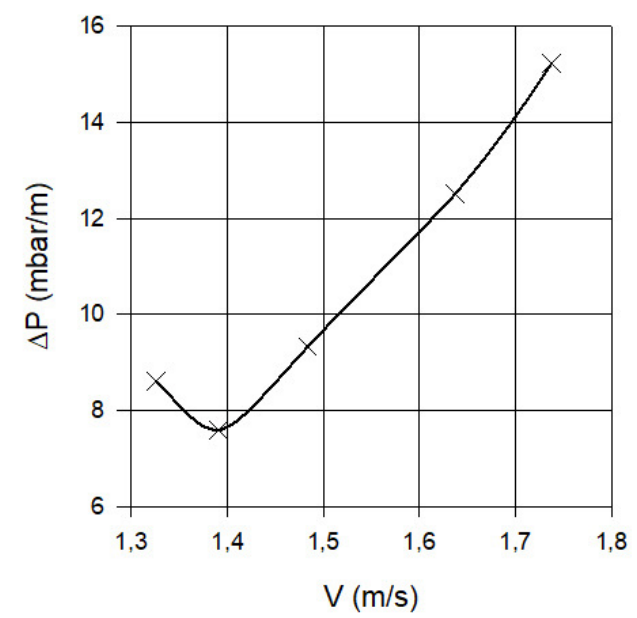

(c) Areia a $15 \%$ em tubo de $4 "$

Figura 21 - Curvas $\vee X \Delta P$ para areia a 15\% (continuação)

Os ensaios de bombeamento de areia demonstraram velocidade de deposição entre $1,3 \mathrm{~m} / \mathrm{s}$ e 2,2 ms. As mínimas perdas de carga estiveram entre 7,5 $\mathrm{mbar} / \mathrm{m}$ e $9,5 \mathrm{mbar} / \mathrm{m}$.

Nos ensaios com minério de ferro a dificuldade foi a quantidade de material disponível para os ensaios. Foram feitos todos os ensaios, mas em um deles, o ensaio no duto de 3" para concentração de $15 \%$ não se chegou ao ponto de carga mínima. No entanto, devido à falta de material, este ensaio não pode ser refeito.

A curva obtida no ensaio com minério de ferro a $15 \%$ de sólidos no duto de 3 " pode ser comparada com um escoamento newtoniano, ou um escoamento de água. Isto pode ter acontecido por conta de uma parte significativa do material ter ficado depositada no fundo da caixa de bomba, ou seja, o escoamento em 
si ocorreu a uma concentração de sólidos menor que $15 \%$, resultando num comportamento aparentemente newtoniano. O fenômeno também foi observado no ensaio com carbonatito, porém este pôde ser refeito. A solução encontrada para resolver o problema de deposição no fundo do tanque foi inserir um agitador portátil ao sistema, como se pode observar na Figura 11.

As Figura 22- Curvas $\mathrm{V} X \Delta \mathrm{P}$ para ferro a 15\% (continua)Figura 22, 24 e 25 mostram, respectivamente, as curvas adquiridas nos ensaios com minério de ferro em concentrações mássicas de 15\%, 30\% e 50\%.

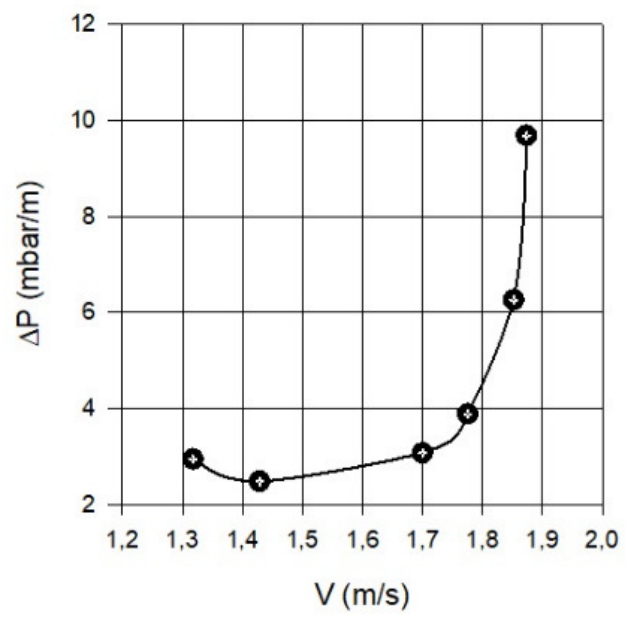

(a) Minério de ferro a $15 \%$ em tubo de $2 "$

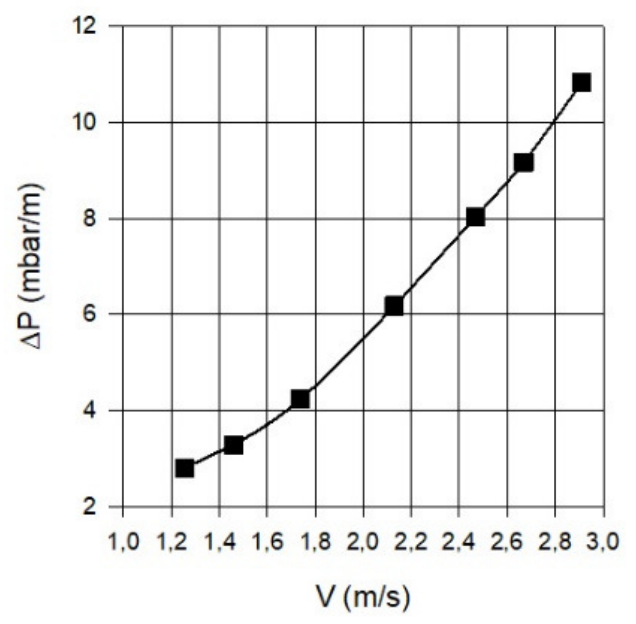

(b) Minério de ferro a 15\% em tubo de 3"

Figura 22- Curvas $\mathrm{V} X \mathrm{P}$ para ferro a $15 \%$ (continua) 


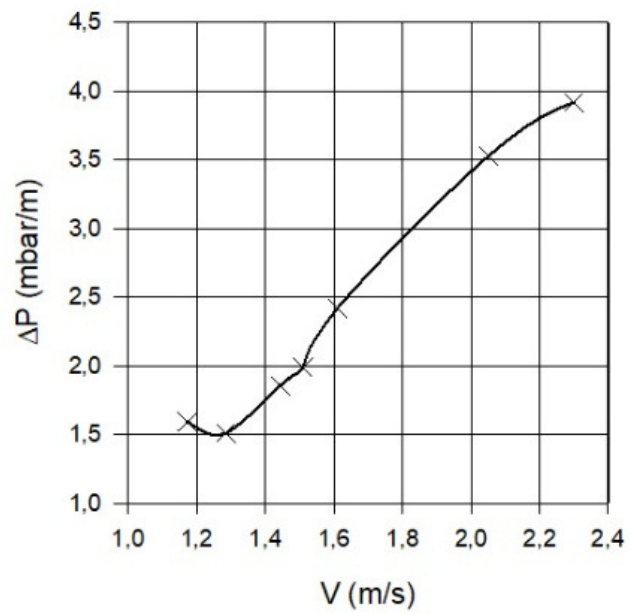

(c) Minério de ferro a $15 \%$ em tubo de $4 "$

Figura 22 - Curvas $V X \triangle P$ para ferro a $15 \%$ (continuação)

Os ensaios de bombeamento de minério de ferro a $15 \%$ demonstraram velocidade de deposição entre $1,3 \mathrm{~m} / \mathrm{s}$ e 2,2 m/s. As mínimas perdas de carga estiveram entre $7,5 \mathrm{mbar} / \mathrm{m}$ e $9,5 \mathrm{mbar} / \mathrm{m}$.

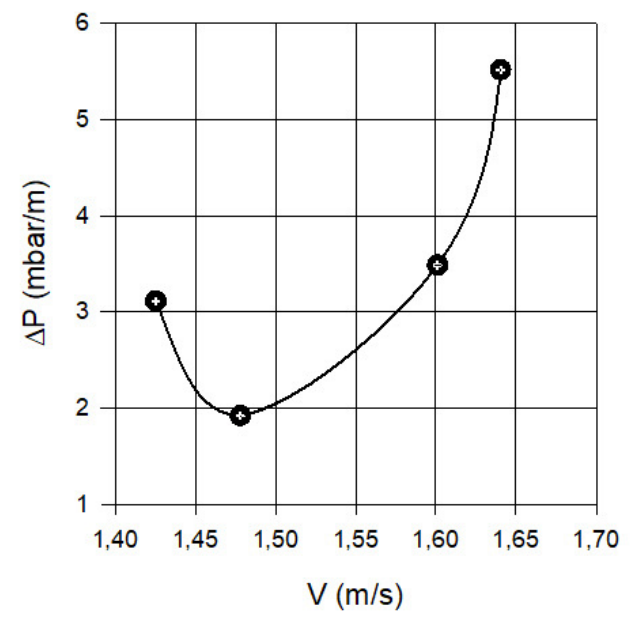

(a) Minério de ferro a $30 \%$ em tubo de $2 "$

Figura 23- Curvas V X $\Delta \mathrm{P}$ para ferro a $30 \%$ (continua) 


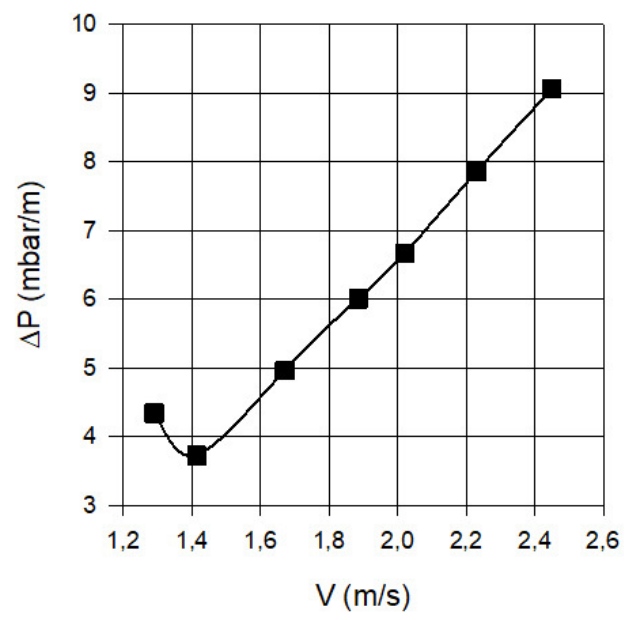

(b) Minério de ferro a $30 \%$ em tubo de 3"

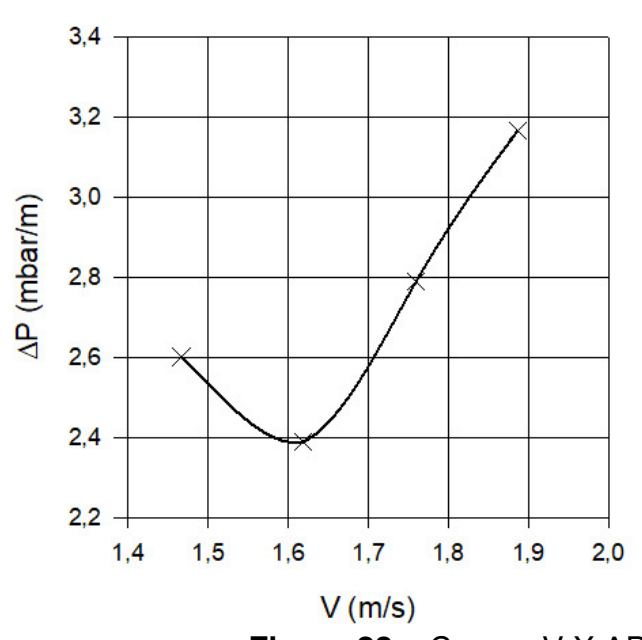

(c) Minério de ferro a $30 \%$ em tubo de $4 "$

Figura 23 - Curvas $V X \Delta$ para ferro a $30 \%$ (continuação)

A ¡Error! No se encuentra el origen de la referencia. mostra as curvas resultantes dos ensaios de bombeamento de minério ferro a $30 \%$ de concentração mássica. Pode-se perceber que a velocidade no duto de 3 " foi menor que no duto de 2". No entanto, os modelos de velocidade de deposição indicam que conforme aumentamos o diâmetro do tubo a velocidade de deposição também aumenta.

Atribui-se a velocidade mais baixa no duto de 3" à falha na operação do sistema que, como já foi dito, resultou em material depositado no fundo da caixa de bomba. Na prática, a polpa bombeada neste ensaio teve uma concentração de sólidos menor do que a alimentada no tanque, o que pode ser o motivo de uma velocidade de deposição mais baixa. A falta de material impediu a realização de novos ensaios para rever este valor. 


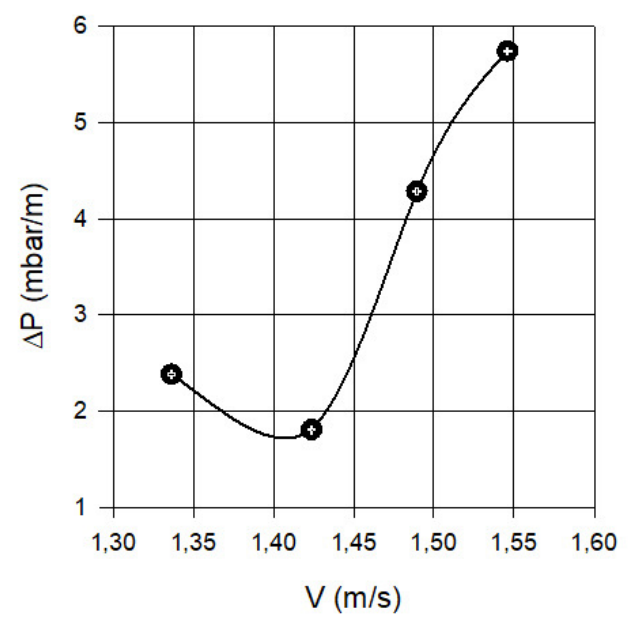

(a) Minério de ferro a $50 \%$ em tubo de 2"

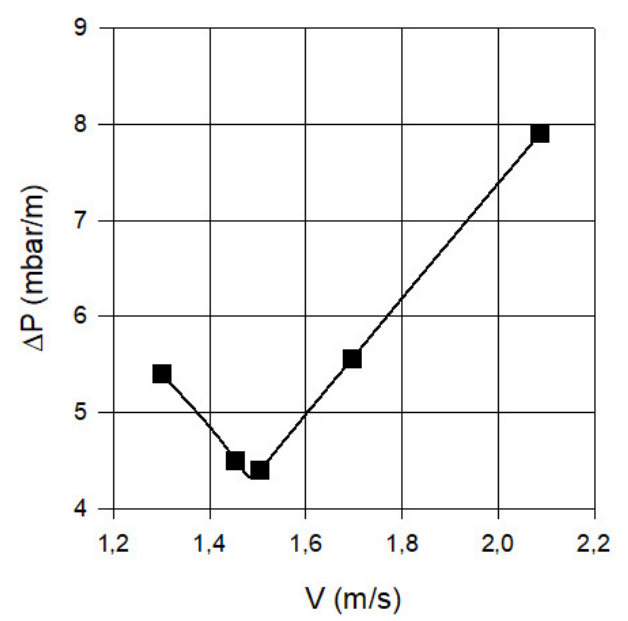

(b) Minério de ferro a $50 \%$ em tubo de 3"

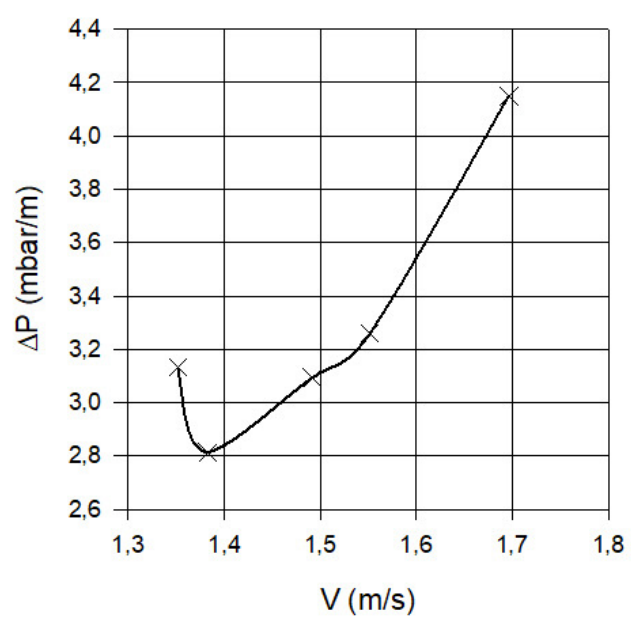

(c) Minério de ferro a $50 \%$ em tubo de $4 "$

Figura 24-Curvas $V X \triangle P$ para ferro a $50 \%$

Nos ensaios de bombeamento com minério de ferro a 50\% (Figura 24) observou-se o aumento da velocidade de deposição do duto de 2" para o duto 
de 3", no entanto houve uma queda do duto de 3" para o duto de 4". Pode-se observar, no entanto uma pequena disfunção na curva do bombeamento de 4" próximo à velocidade $1,5 \mathrm{~m} / \mathrm{s}$. Acredita-se que, a partir deste ponto, a turbulência do tanque diminuiu formando uma camada de material depositado no fundo do tanque e causando a diminuição da quantidade de sólidos dentro do tubo. Tal redução na concentração de sólidos acarretou a diminuição da velocidade de deposição a partir daí o mesmo fenômeno foi observado no escoamento em 4" com Cw 15\% (observado na ;Error! No se encuentra el origen de la referencia. $-c)$.

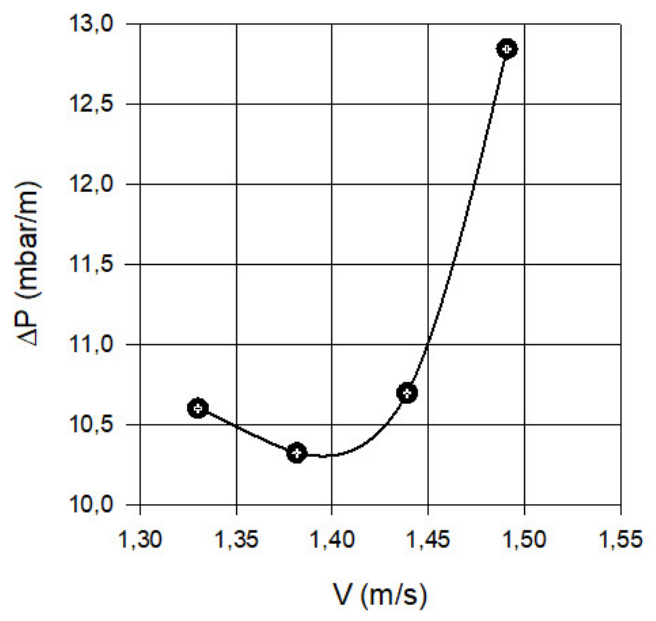

(a) Minério de carbonatito a $15 \%$ em tubo de 2"

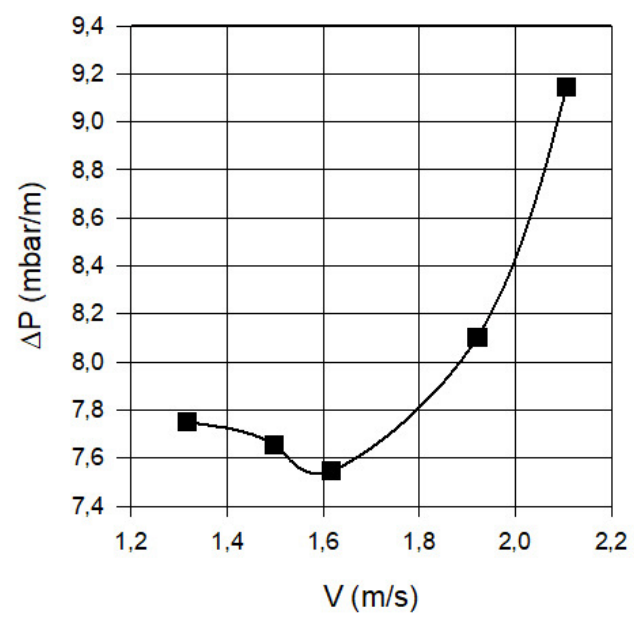

(b) Minério de carbonatito a $15 \%$ em tubo de 3"

Figura 25-Curvas $\mathrm{V} X \Delta \mathrm{P}$ para carbonatito a $15 \%$ (continua) 


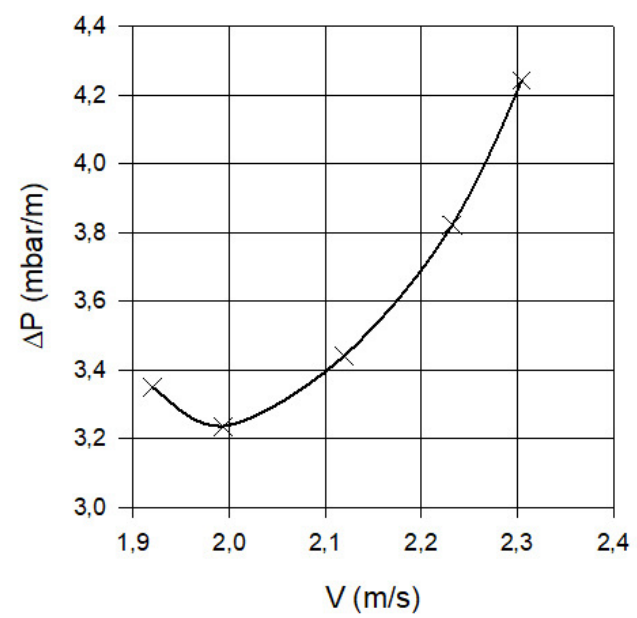

(c) Minério de carbonatito a $15 \%$ em tubo de 4"

Figura 25 - Curvas $\mathrm{VX} \Delta \mathrm{P}$ para carbonatito a 15\% (continuação)

Com o carbonatito com $\mathrm{Cw}$ de $15 \%$ obteve-se um comportamento de $\mathrm{Vd}$ compatível com o esperado. Estes ensaios foram refeitos depois que foram observadas deficiências na operação do sistema e implantarmos soluções.

Assim sendo, as velocidades de deposição aumentaram conforme aumentou o diâmetro do tubo, como se pode observar na ¡Error! No se encuentra el origen de la referencia..

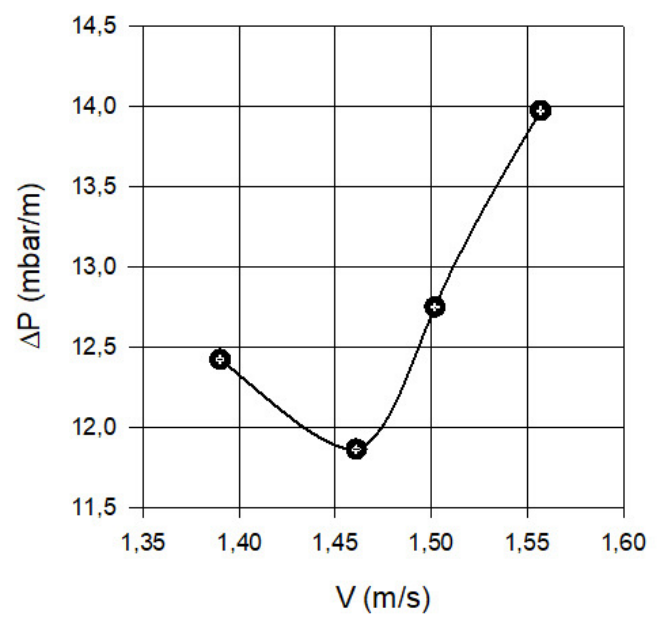

(a) Minério de carbonatito a $30 \%$ em tubo de 2"

Figura 26- Curvas $\mathrm{V} X \Delta \mathrm{P}$ para carbonatito a $30 \%$ (continua) 


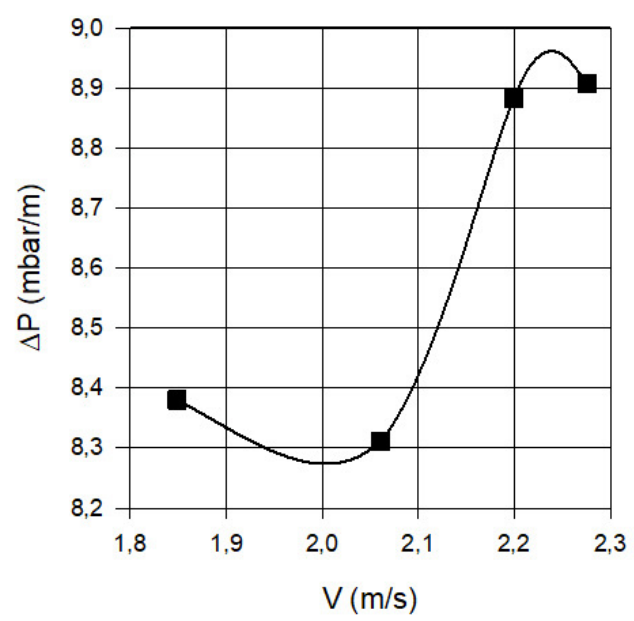

(b) Minério de carbonatito a $30 \%$ em tubo de 3"

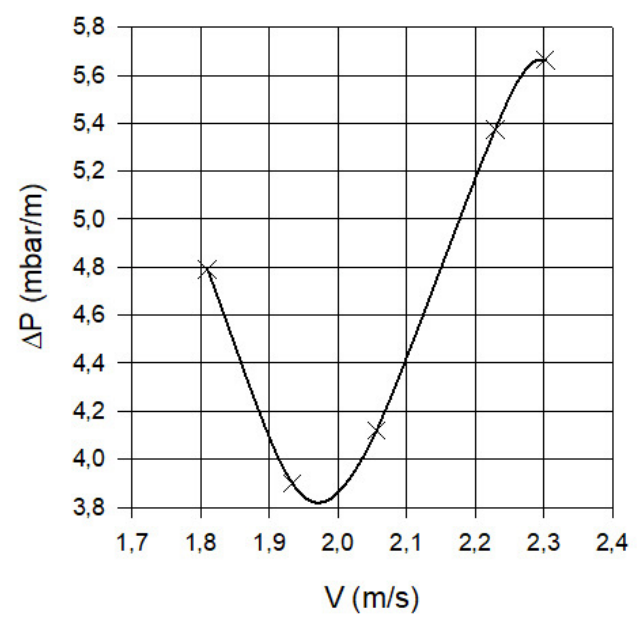

(c) Minério de carbonatito a $30 \%$ em tubo de 4"

Figura 26-Curvas $V X \Delta P$ para carbonatito a $30 \%$ (continuação)

Nos ensaios do carbonatito com $\mathrm{Cw} 30 \%$ as velocidades observadas nas curvas criadas mostraram um valor menor para o duto de 4" do que para o duto de 3". A falta de estabilidade durante o ensaio de 3" foi um empecilho para a determinação de mais pontos da curva e, consequentemente, um resultado mais acurado da velocidade no duto de 3 ". 


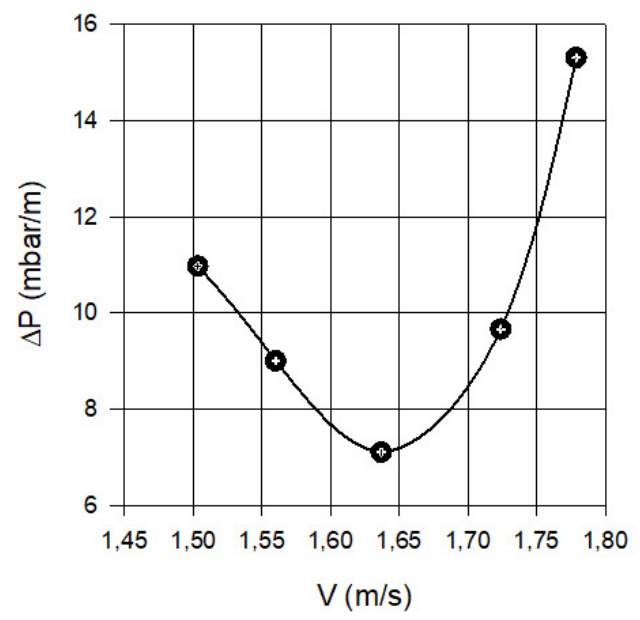

(a) Minério de carbonatito a $50 \%$ em tubo de 2"

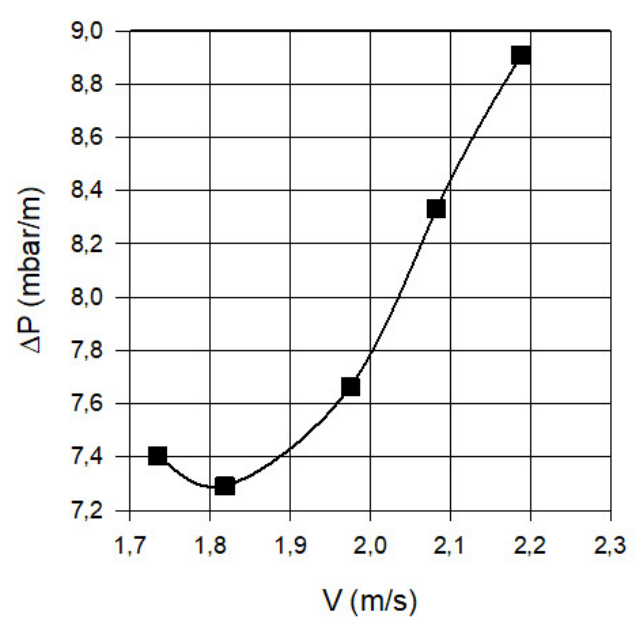

(b) Minério de carbonatito a $50 \%$ em tubo de $3 "$

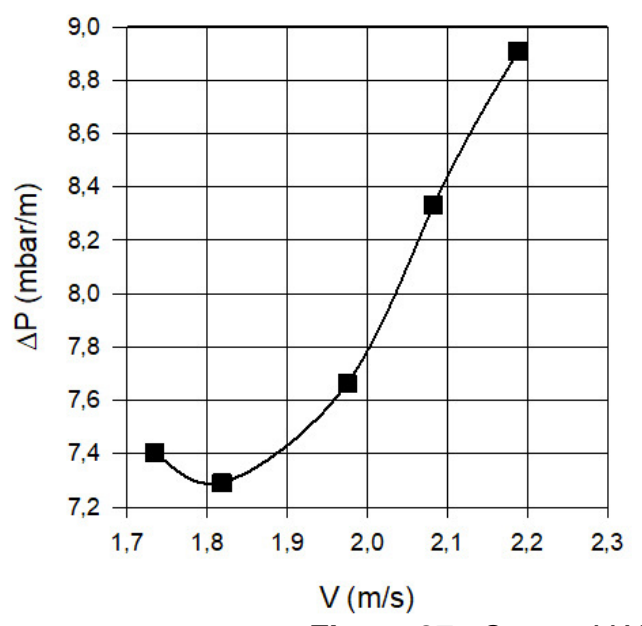

(c) Minério de carbonatito a $50 \%$ em tubo de 4"

Figura 27-Curvas $V X \triangle P$ para carbonatito a $50 \%$

Com o carbonatito com $\mathrm{Cw}$ de $50 \%$ foi obtido um comportamento de $\mathrm{Vd}$ compatível com o esperado. Os ensaios foram refeitos depois que foram 
observadas deficiências na operação do sistema e soluções foram implantadas.

Assim sendo, as velocidades de deposição aumentaram conforme aumentou o diâmetro do tubo, como se pode observar na Figura 27.

Todos os valores de velocidade de deposição e as perdas de carga mínimas para os escoamentos que foram estudados durante os ensaios de bombeamento estão compiladas na Tabela 5 .

Tabela 5 - Compilação de velocidades de deposição e perdas de carga mínimas de escoamento

\begin{tabular}{|c|c|c|c|c|}
\hline Material & Cw (\%) & $D(m)$ & $\begin{array}{c}\mathrm{Vc} \\
(\mathrm{m} / \mathrm{s})\end{array}$ & $\Delta P(m b a r)$ \\
\hline \multirow{3}{*}{ Areia } & \multirow{3}{*}{15} & 0,051 & 1,76 & 8,20 \\
\hline & & 0,076 & 2,20 & 9,40 \\
\hline & & 0,102 & 1,39 & 7,50 \\
\hline \multirow{9}{*}{ Ferro } & \multirow{3}{*}{15} & 0,051 & 1,43 & 2,47 \\
\hline & & 0,076 & - & - \\
\hline & & 0,102 & 1,26 & 1,50 \\
\hline & \multirow{3}{*}{30} & 0,051 & 1,47 & 1,90 \\
\hline & & 0,076 & 1,41 & 3,7 \\
\hline & & 0,102 & 1,64 & 2,40 \\
\hline & \multirow{3}{*}{50} & 0,051 & 1,41 & 1,75 \\
\hline & & 0,076 & 1,44 & 4,37 \\
\hline & & 0,102 & 1,38 & 2,80 \\
\hline \multirow{9}{*}{ Carbonatito } & \multirow{3}{*}{15} & 0,051 & 1,38 & 10,32 \\
\hline & & 0,076 & 1,60 & 7,54 \\
\hline & & 0,102 & 1,99 & 3,20 \\
\hline & \multirow{3}{*}{30} & 0,051 & 1,46 & 11,86 \\
\hline & & 0,076 & 2,02 & 8,25 \\
\hline & & 0,102 & 1,96 & 3,83 \\
\hline & \multirow{3}{*}{50} & 0,051 & 1,64 & 7,09 \\
\hline & & 0,076 & 1,80 & 7,30 \\
\hline & & 0,102 & 1,83 & 3,75 \\
\hline
\end{tabular}

Os ensaios de bombeamento apresentaram, portanto, dificuldades. Percebe-se que um dos pontos de controle mais importantes neste tipo de ensaio é a preservação da alimentação da bomba. Sempre que houver deposição de partículas na caixa de bombas os resultados serão prejudicados, pois o 
escoamento não estará mais ocorrendo conforme o planejado para o ensaio. A redução da concentração volumétrica causada pela deposição das partículas na caixa de bombas interfere em diversas variáveis do escoamento, a saber:

- concentração de sólidos: diferença entre a proporção de sólido e líquido no escoamento.

- densidade da polpa: quando há grãos de diferentes mineralogias (como no caso do minério de ferro), as partículas mais densas ficarão depositadas na caixa de bomba enquanto as mais leves continuarão no fluxo de alimentação da bomba, ou seja, o ensaio estará sendo feito com uma polpa de menor densidade

- granulometria: quando há partículas muito grossas, estas terão uma tendência maior de depositar na caixa de bomba enquanto as partículas mais finas continuarão sendo transportadas, acarretando um escoamento com partículas mais finas do que a planejada para o ensaio.

\subsubsection{Velocidade de deposição}

Nesta seção foi feita a comparação entre os resultados de Vd obtidos com o uso dos modelos de Durand e Condolios (1952), Wasp et al. (1977) e Wilson et al. (2006) com os valores observados em laboratório e uma análise geral do que pode ser dito a partir dos resultados de Vd para os três minérios ensaiados neste trabalho. 

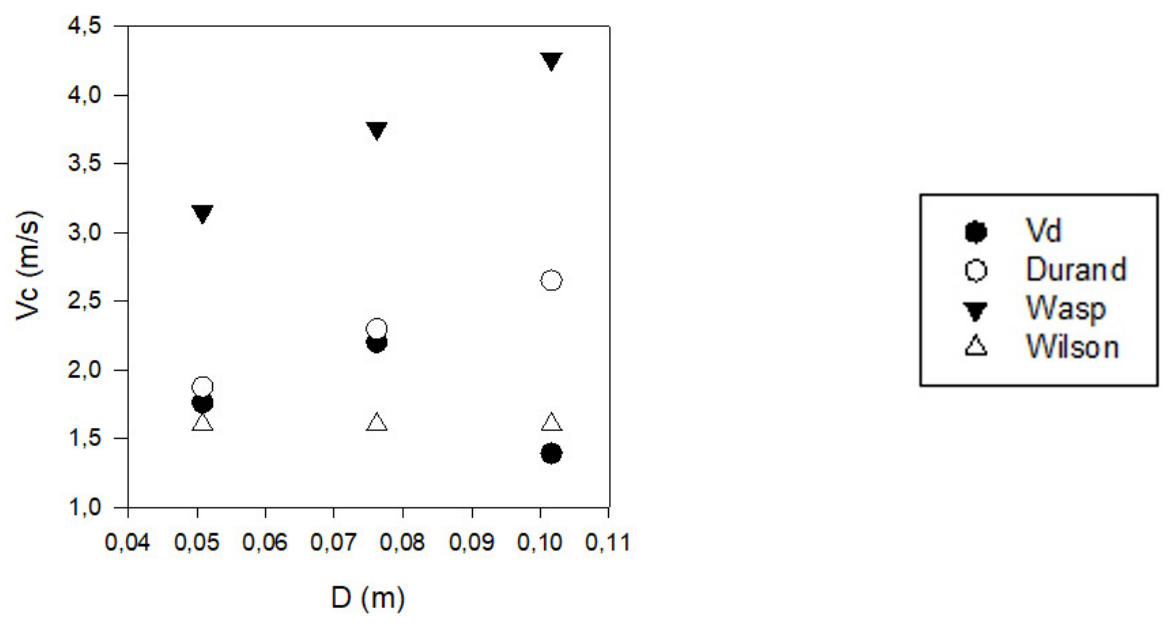

Areia a $15 \%$

Figura 28 - Comparação de Vd real com os modelos para areia

O modelo de Durand (1952) aderiu bem aos resultados de 2 e 3", mas quando observamos o valor obtido no tubo de 4", percebemos discrepâncias, principalmente porque tanto o modelo de Durand (1952) quanto o de Wasp et al. (1977) indicam aumento na Vd com o aumento do diâmetro do tubo, o que não aconteceu nos ensaios com areia.

Importante lembrar que o modelo de Wilson é aplicável somente para tubulações a partir de 4" por isto, quando aplicamos aos nossos escoamentos, os valores de Wilson não mudam com o diâmetro do tubo. O resultado obtido no duto de 4" é coerente com o modelo de Wilson.

Conforme era previsto, os valores de Vd obtidos pelo intermédio dos modelos são sempre maiores que os observados no laboratório. Nos diâmetros menores, Durand mostrou discrepâncias da ordem de $6,5 \%$, enquanto no duto de 4" a diferença foi de $90 \%$. Os valores de Wasp foram supervalorizados de $70 \%$ a $200 \%$ enquanto Wilson superestimou a velocidade de deposição na ordem de $15 \%$ para o duto de 4 ". 


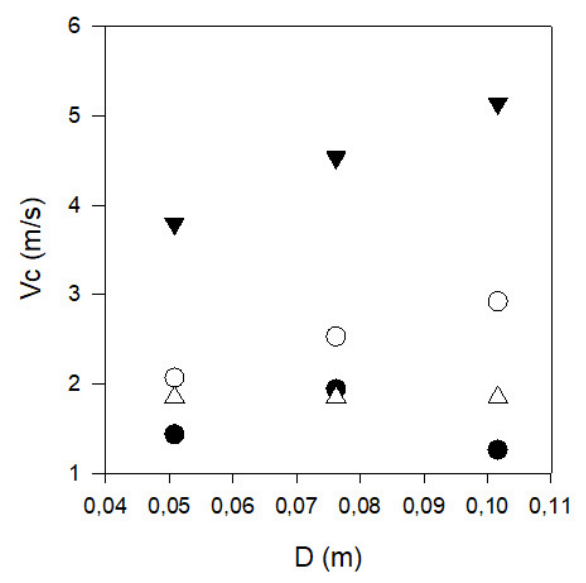

Minério de ferro a $15 \%$

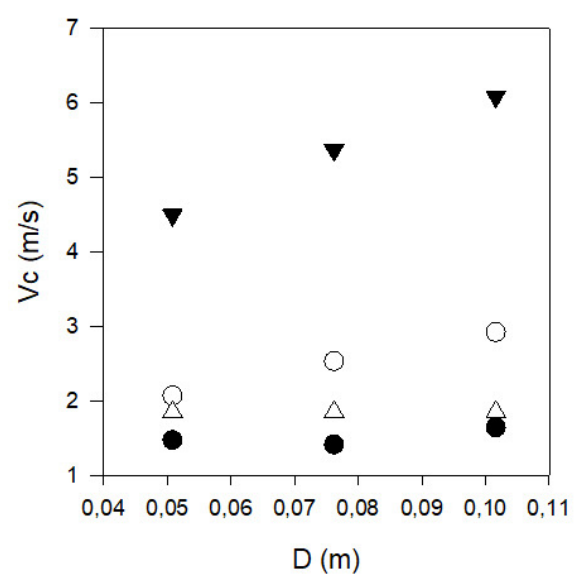

- Vd

Durand

> Wasp

$\triangle$ Wilson

Minério de ferro a $30 \%$

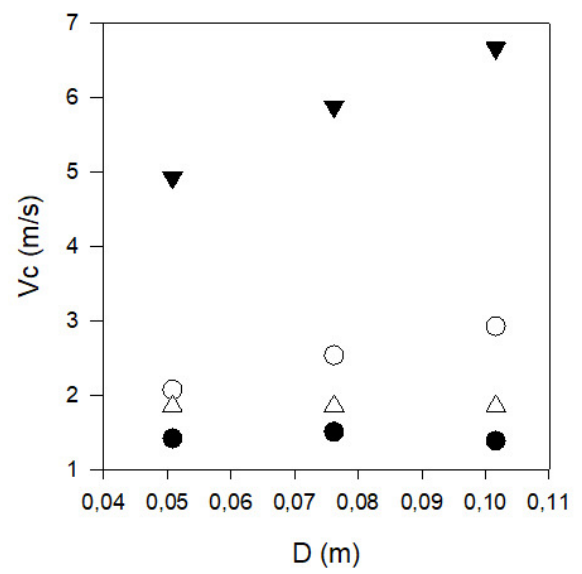

Minério de ferro a $50 \%$

Figura 29 - Comparação de Vd real com os modelos para ferro 
Ao fazer as análises comparativas para os ensaios de minério de ferro, é necessário salientar que houve problemas em alguns ensaios por conta das questões operacionais que já foram comentadas.

Assim como com a areia, todos os modelos superestimaram a $\mathrm{Vd}$ em comparação com o resultado laboratorial. Wasp é o modelo que mais se distancia dos valores reais de velocidade para os escoamentos. As diferenças nos modelos de Wasp são da ordem de 165\% a 383\%. Já Durand tem diferenças que variam entre $30 \%$ e $130 \%$, enquanto Wilson, para o duto de 4", superestimou a Vd entre $12 \%$ e $46 \%$.
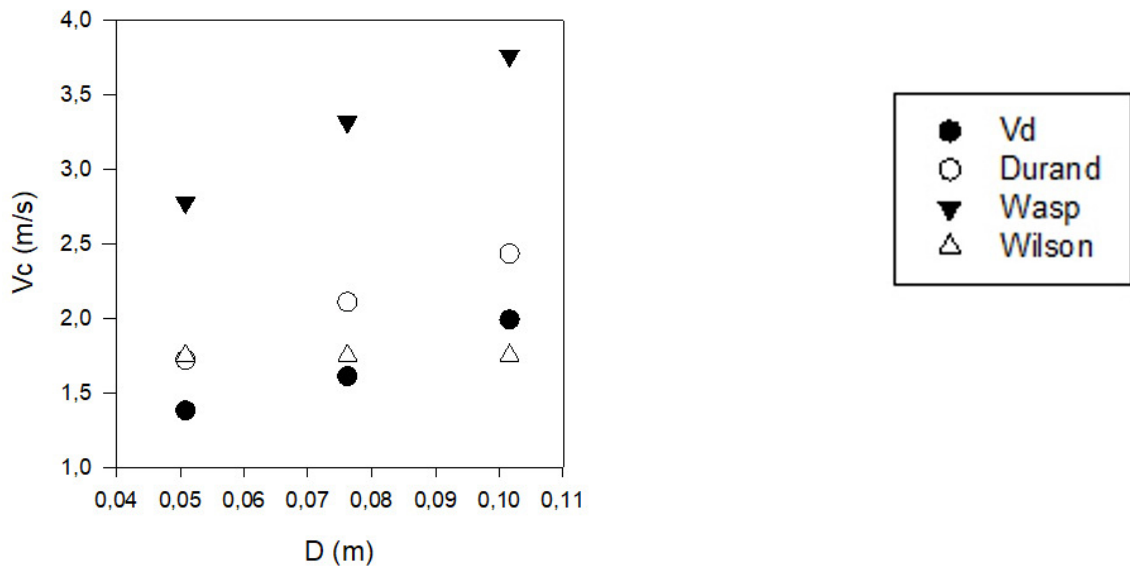

Figura 30 - Comparação de Vd real com os modelos para carbonatito (continua) 
Carbonatito a $15 \%$

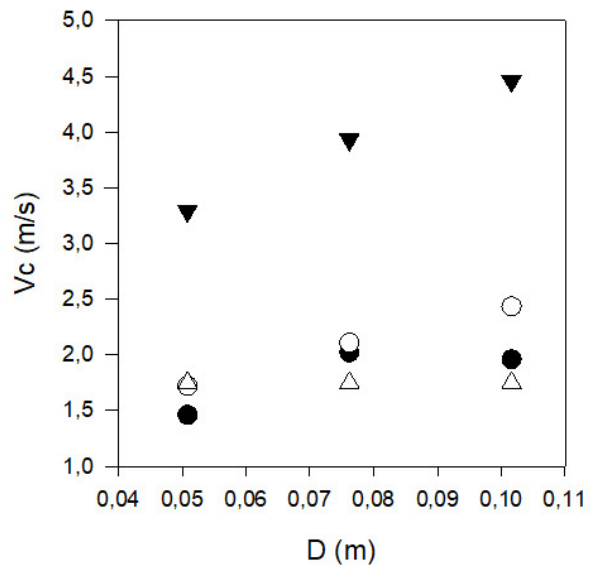

Carbonatito a $30 \%$

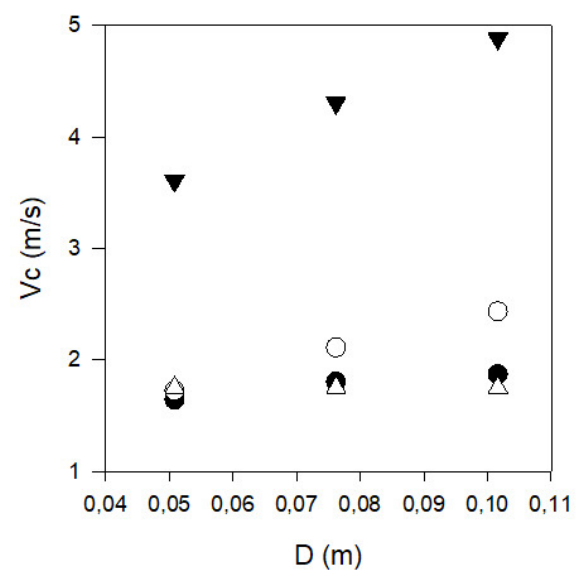

Carbonatito a $50 \%$

Figura 35 - Comparação de Vd real com os modelos para carbonatito (continuação)

Os resultados de $\mathrm{Vd}$ para o carbonatito variaram em relação aos valores previstos pelos modelos entre $160 \%$ e $4 \%$. Como nos outros casos, o método de Wasp foi o que mais superestimou a Vd. Boas adesões foram encontradas entre os números reais e os de Durand, com variações entre $4 \%$ e $30 \%$. Neste caso, o modelo de Wilson subestimou o valor de Vd encontrado para os dutos de 4" em todas as concentrações.

Apesar da alta densidade o minério de ferro apresentou velocidades de deposição menores que a areia e o carbonatito. Isto porque o tamanho dos grãos era bem menor. As maiores velocidades de deposição foram as da areia. 
Mesmo tendo resultados somente para concentrações mais baixas, de $15 \%$ em massa, as velocidades necessárias para o escoamento completo foram mais altas que as necessárias para o escoamento do carbonatito.

Quanto à interferência do diâmetro do duto na velocidade do escoamento, a prática demonstrou variações. No caso da areia, a velocidade aumentou do duto de 2" para o duto de 3", no entanto diminuiu para o duto de 4". Para o ferro a $15 \%$ e a $50 \%$, observamos o mesmo efeito. Já para o carbonatito, o efeito notado foi diferente: houve o aumento da velocidade de deposição com 0 aumento do duto em todos os casos. A deposição dos materiais na caixa de bomba e consequente redução da concentração de sólidos no escoamento, como já foi dito anteriormente, é o principal motivo para que tais variações tenham ocorrido.

\subsubsection{Perda de carga}

Em se tratando das perdas de carga, pôde-se observar durante os ensaios variações muito grandes. Por conta destas variações, cada ponto da curva é formado pela média de uma série de medidas tomadas a uma mesma velocidade de rotação da bomba. Considera-se que as incertezas atreladas às medidas das perdas de cargas são grandes.

Dito isto, em comparação com os modelos testados, praticamente todos os valores obtidos em laboratório foram muito maiores que os resultados dos modelos.

As Figura 31 a 39 demonstram a relação entre os valores dos modelos versus os resultados de laboratório. Pode-se observar uma grande discrepância entre eles.

As linhas retas correspondem à correlação perfeita entre os valores obtidos com o uso dos modelos e no laboratório. Elas não têm $45^{\circ}$ de inclinação devido à necessidade de expandir a escala vertical. 


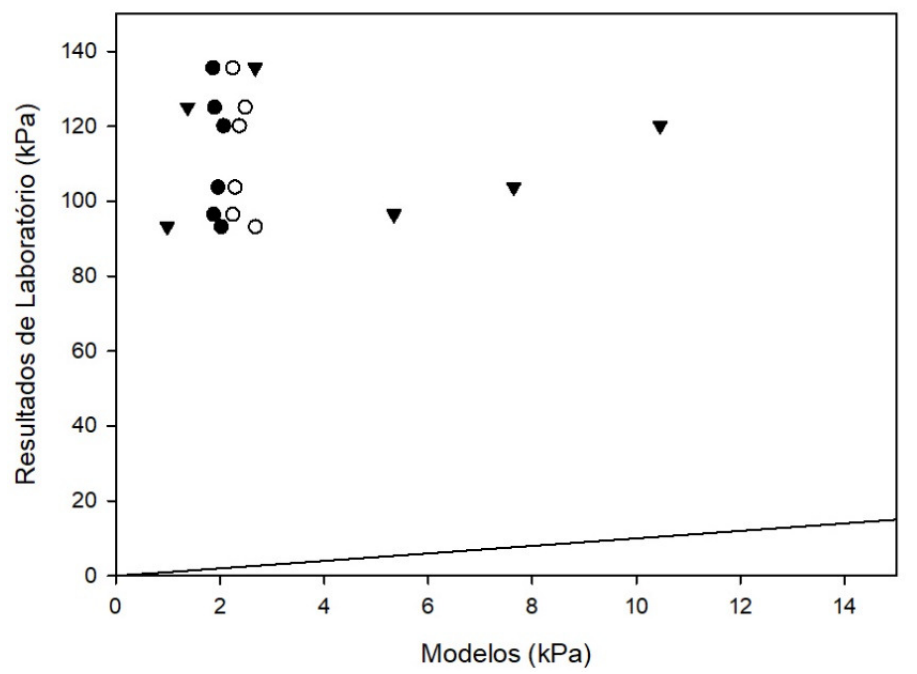
- Durand vs DeltaP
- Wasp vs DeltaP
$\nabla$ Newitt vs DeltaP Correlação $=1$

Figura 31 - Comparação de $\Delta \mathrm{P}$ real com os modelos para areia

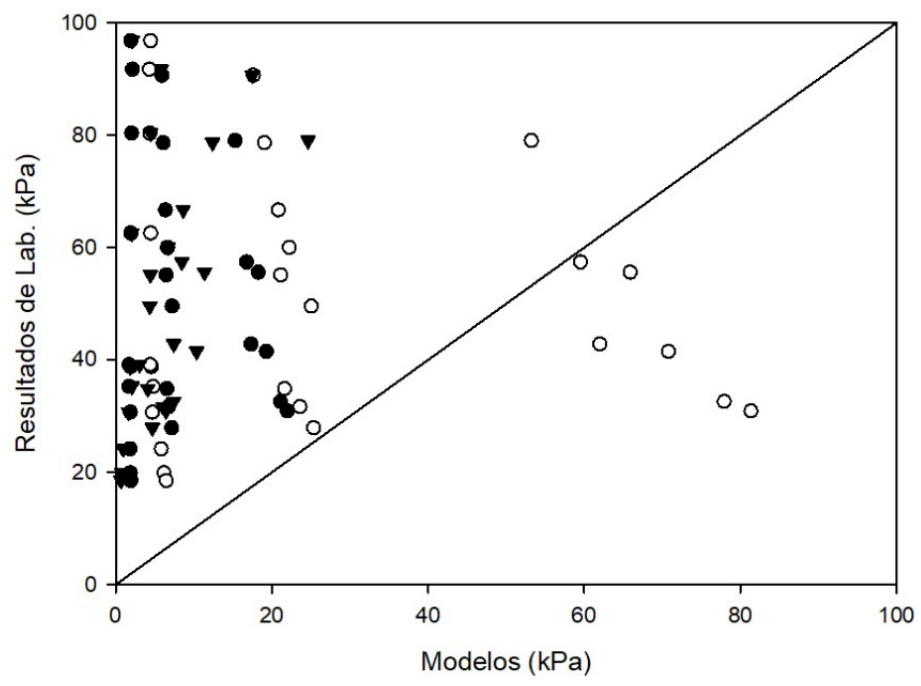

- Durand vs DeltaP

- Wasp vs DeltaP

$\nabla$ Newitt vs DeltaP Correlação $=1$

Figura 32 - Comparação de $\Delta \mathrm{P}$ real com os modelos para ferro 

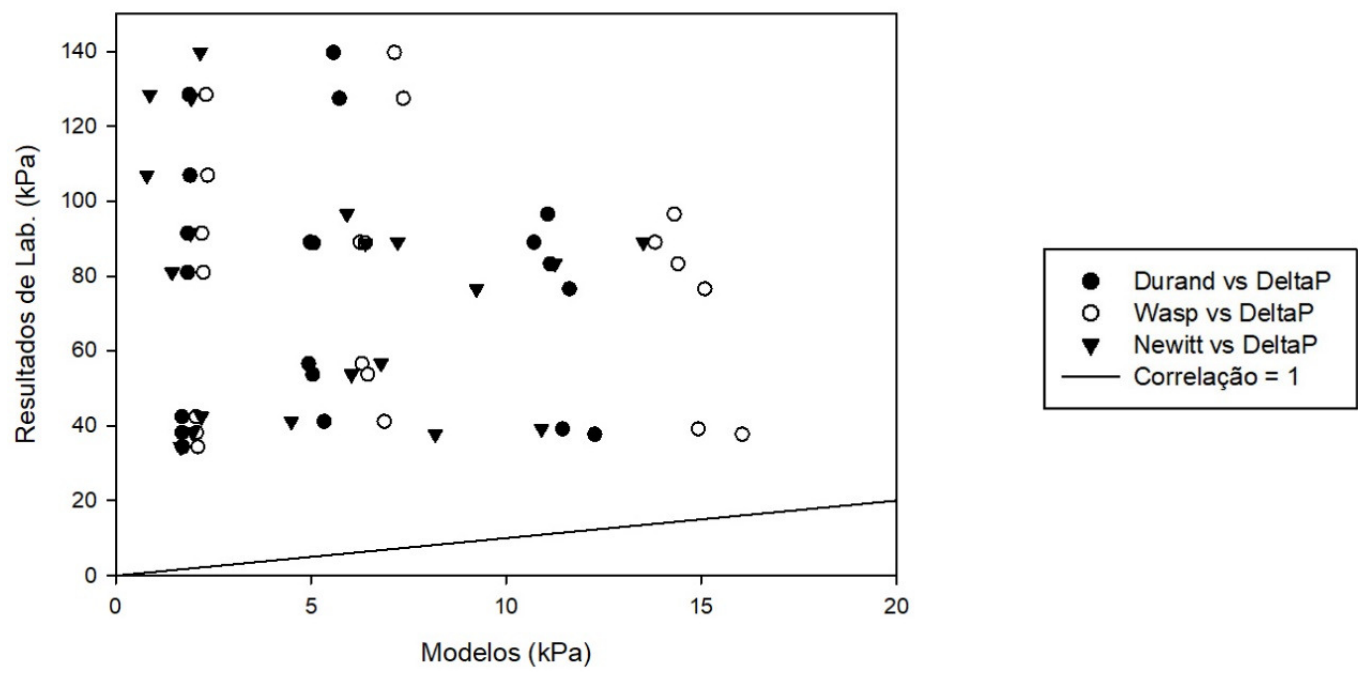

Figura 33 - Comparação de $\Delta \mathrm{P}$ real com os modelos para carbonatito

A maior parte dos cálculos de perda de carga deram resultados muito menores que os obtidos em laboratório.

Chaves, 2012, apesar de citar o modelo de Durand em seu livro, indica o uso de perdas de carga iguais à da água para polpas com concentrações abaixo de $40 \%$ de sólidos em fluxos homogêneos, Lei da Potência para escoamentos de polpas homogêneas acima de $40 \%$ de sólidos e o método de duas camadas de Wasp para fluxos heterogêneos. No entanto, nos exercícios resolvidos, utiliza o diagrama da Humboldt para os cálculos de perda de carga.

Abulnaga (2002) também não indica o uso de modelos de predição de perda de carga para os estudos de viabilidade e projetos de sistemas de bombeamento de polpa. São apresentados ábacos de perda de carga versus eficiência da bomba e taxa de escoamento para este fim.

Talmon (2016) diz que o melhor que se pode fazer durante o projeto de um sistema de bombeamento é uma planta piloto.

Nenhum dos nossos fluxos foi homogêneo, o que também dificulta o uso de modelos de uma única camada. 


\section{CONCLUSÃo}

A operação de um sistema de bombeamento é complexa. Houve, sobretudo, dificuldades para manter a alimentação da bomba com polpas de características constantes. Esta dificuldade também é encontrada nas usinas de beneficiamento, onde qualquer mudança na qualidade do minério que alimenta a usina pode gerar fluxos com maior ou menor concentração de sólidos, ou diferentes granulometrias, alterando completamente 0 comportamento do escoamento da polpa dentro da tubulação. Nas operações de lavra por dragagem observa-se uma dificuldade ainda maior na operação, uma vez que o material é muito heterogêneo e o operador da draga deve ter muita experiência para manter a concentração de sólidos no fluxo. Em minerodutos, os grandes reservatórios de polpa devem ser dimensionados de maneira que nenhum material fique depositado no fundo e a polpa alimentada ao minerodutos seja sempre homogênea, o que é muito custoso.

Os modelos de velocidade de deposição são superestimados. Por um lado, observando as dificuldades da operação, é prudente superestimar a velocidade de deposição a fim de evitar a obstrução do duto. Por outro lado, fatores como o desgaste dos equipamentos, alto consumo de energia e alto custo de investimento neste tipo de projeto requerem cautela quanto ao superdimensionamento.

Conforme indicado por vários autores (ABULNAGA, 2002) (CHAVES, 2012), (TALMON, 2016) e observado na prática, os modelos de predição de perda de carga existentes não são boas medidas para o uso direto nos projetos de sistemas de bombeamento. Eles podem ser usados como comparação entre o comportamento do escoamento de polpas ou entre polpa e a água, mas são muitas variáveis que interferem no valor de $\Delta \mathrm{P}$, incluindo o tipo de bomba, a geometria da bomba e do sistema, que não são características da polpa mineral em si. De fato, Brum (2017) aponta que existem vários modelos empíricos para transporte hidráulico de sólidos, e destes podem ser encontrados defensores, corretores e até mesmo opositores de alguns modelos. Ábacos de fabricantes de bombas ou até mesmo dados de operações similares são medidas de perda de carga mais adequadas ao uso em projetos. 


\section{REFERÊNCIAS BIBLIOGRÁFICAS}

1. ABULNAGA, B. Slurry Systems Handbook. New York: McGraw-Hill, 2002. $628 \mathrm{p}$.

2. BARNES, H. A.; HUTTON, J. F.; WATERS, K. F. R. S. An Introduction to Rheology. 3. ed. Amsterdan: Elsevier, 1993. 201 p.

3. BROWN, N. P.; HEYWOOD, N. I. Slurry Handling Design of SolidLiquid Systems. Essex and New York: Elsevier Science Publishrs Ltd., 1991. $687 \mathrm{p}$.

4. BRUM, S. M. Influência da Granulometria, concentração de sólidos e composição mineralógica nas propriedades reológicas e variáveis de transporte de polpa de bauxita por mineroduto. Universidade Federal do Pará. Belém. 2017.

5. CHAVES, A. P. Teoria e Prática do Tratamento de Minérios Bombeamento de polpa e classificação. 4. ed. São Paulo: Oficina de Textos, v. 1, 2012. 267 p.

6. CHHABRA, R. P.; RICHARDSON, J. F. Non-Newtonian Flow in the Process Industries: Fundamentals and engineering applications. Exford: Butterworth-Heinemann, 1999. 421 p.

7. DIBAKAR, P.; ROUTRAY, A. Prediction of pressure drop for flow of fine coal slurry. International Advanced Research Journal in Science, Engineering and Technology, Chennai, v. 2, n. 8, agosto 2015.

8. DURAND , R. The hydraulic transportation of coal and solid material in pipes. Colloquium on the Hydraulic Transport of Coal. Grenoble: [s.n.]. 1952.

9. DURAND, R.; CONDOLIOS, E. Experimental study of the transport of solids in pipes. Conference of the Society Hydrotechnique de France. Grenoble: [s.n.]. 1952. p. 29-55.

10. GARCIA, L. P.; PINTO, T. C. D. S. Escalonamento de dados de perda de carga em sistemas de bombeamento para polpas heterogêneas de 
quartzo. Unisantana Science and Technology, Santos, v. 4, p. 22-28, julho 2015.

11. GRZINA, A.; ROUDNEV, A.; BURGESS, K. E. Slurry Pumping Manual: A Technical Apllication Guide For Users of Centrifugal Slurry Pumps and Slurry Pumping Systems. Sydney: Warman International Ltd, 2002. 65 p.

12. JACOBS, B. E. A. Design of Slurry Transport Systems. London e New York: Elsevier Applied science, 2005.

13. LAHIRI, S. K. Study on slurry flow modelling in pipeline. National Institute of Technology. DURGAPUR, p. 300. 2010.

14. MIEDEMA, S. A. A head loss model for homogeneous slurry transport for medium sized particles. J. Hydrol. Hydromech, v. 63, n. 1, p. 1-12, 2015.

15. NASCIMENTO, C. R. Reologia e Reometria Aplicadas ao Estudo de Polpas Minerais. Rio de Janeiro: CETEM/MCT, v. 12, 2008. 53 p.

16. NEWITT, D. M. et al. Hydraulic Conveying of Solids in Horizontal Pipes. Transactions of the Institution of Chemical Engineers, London, p. 93110, 1955.

17. OROSKAR, A. R.; TURIAN, R. M. The Critical Velocity in Pipeline Flow of Slurries1. AlChE Journal, v. 26, n. 4, p. 550-558, 1980.

18. PINTO, T. C. D. S. Modelagem da Velocidade Crítica de Transporte de Polpas Minerais Contendo Partículas Grossas. Escola Politécnica da Universidade de São Paulo. São Paulo. 2012.

19.SILVA, R. et al. Settling Suspensions Flow Modelling: A Review. Kona: Powder and Particle Journal, 2015.

20.TALMON, A. TU Delft OpenCourseWare. www.ocw.tudelft.nl, 2016. Disponivel em: <https://ocw.tudelft.nl/courses/dredge-pumps-and-slurrytransport/>. Acesso em: 25 novembro 2017.

21.WASP, E. J.; KENNY, J. P.; GANDHI, R. L. Solid-liquid flow slurry pipeline transportation. Clausthal: Trans Tech Publications, 1977. 
22. WILSON, K. C. et al. Slurry Transport Using Centrifugal Pumps.

Terceira. ed. New York: Slurry Transport Using Centrifugal Pumps, 2006. 